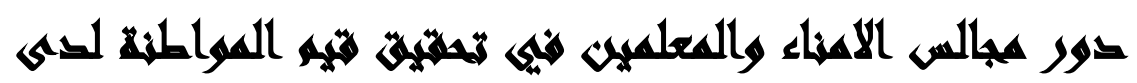

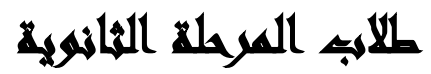

\section{[1r]}

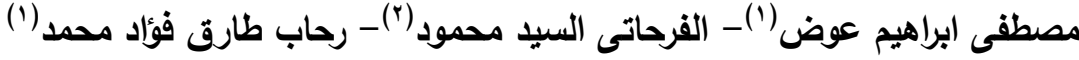

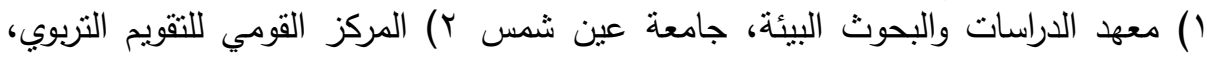

جامعة عين شمس

\section{المستخليه}

يعتبر دور مجالس الامناء والمعلمين في تتمية نقافة المواطنة هاما من خلال اسلوب

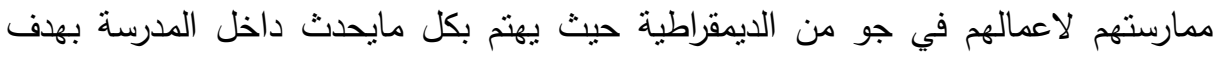
التحسين والتطوير، ويمكن لهجالس الامناء والمعلمين ان تكون اداة فعالة في رعاية وحماية

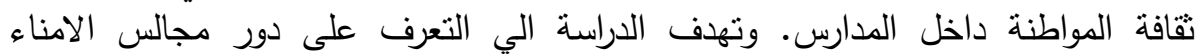

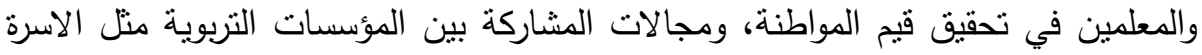

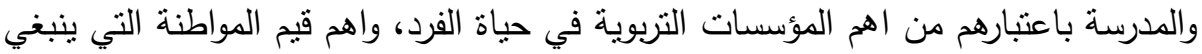

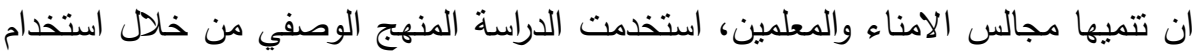

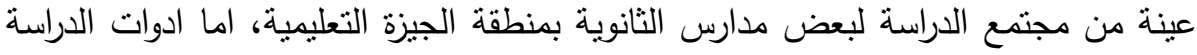

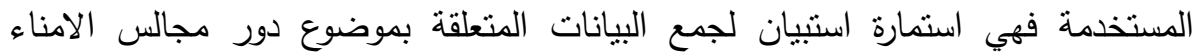

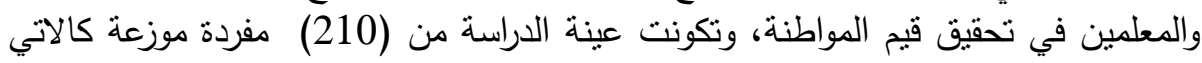

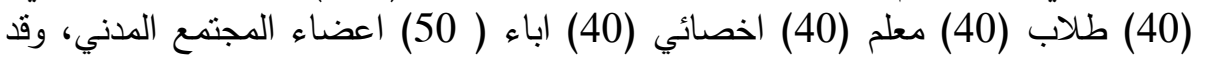

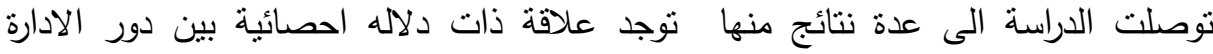

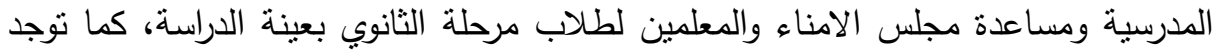

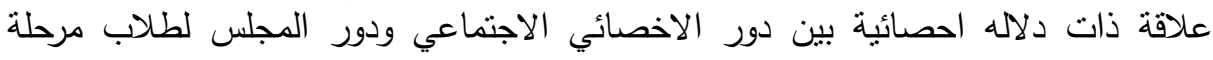

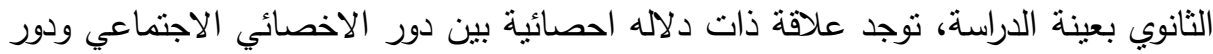

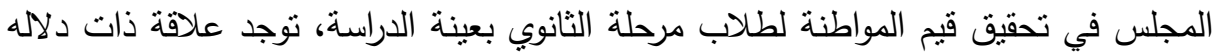



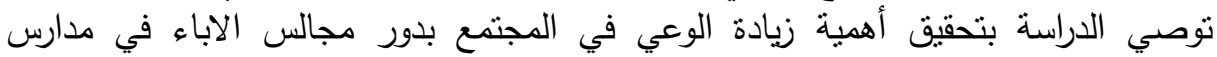

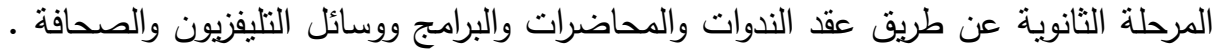

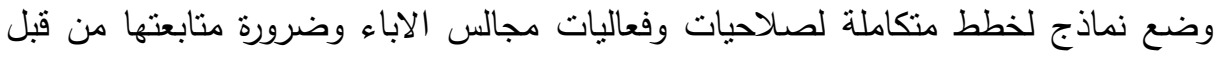

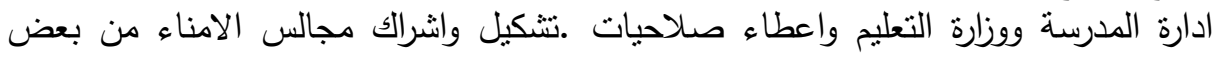

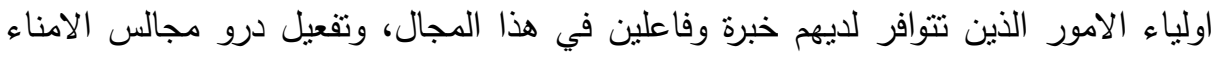

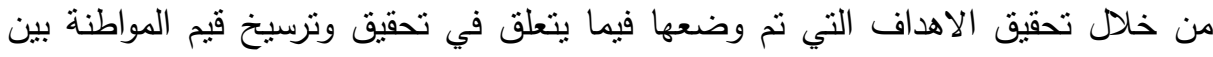

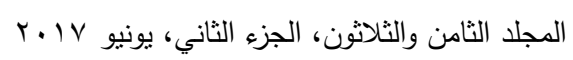


اعضاء المجتمع المدني ( المدرسة الاسرة الجمعيات الخ )، تحقيق اهداف مجالس الأمناء والقضاء علي المظاهر السلبية التي تعترض مجالس الأمناء.

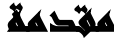

تقوم مجالس الامناء والمعلمين بدورا هاما في ايجاد اسس للتعاون والتربية والتعليم المبني علي اساس التوثيق والتبادل والتكامل فيما بينها بهدف تحقيق العملية التعليمية لاهدافها، تعتبر بهري التنشئة الاجتماعية هي الهدف الأساسي من عمليات التربية وهذه العملية التي ينم من خلالها

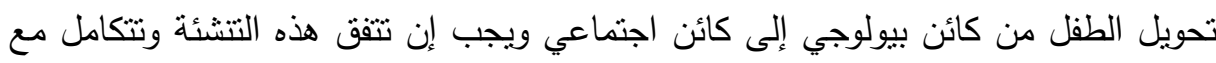

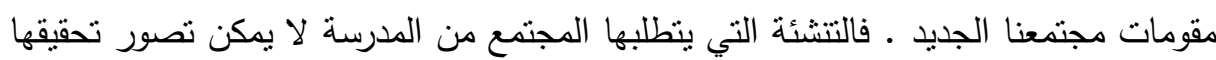

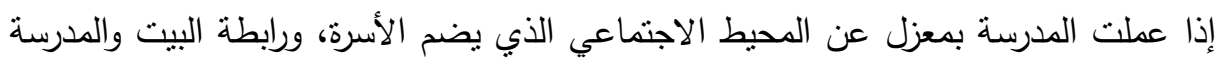

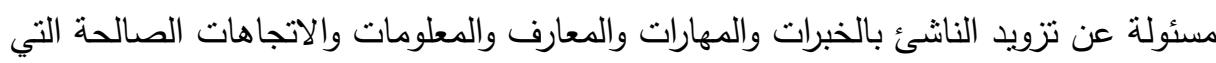

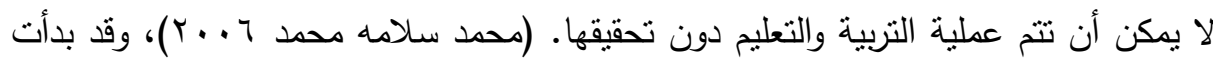



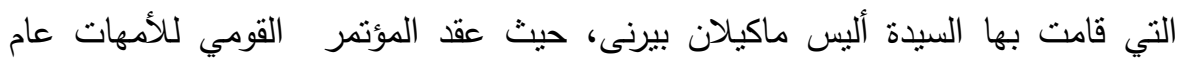

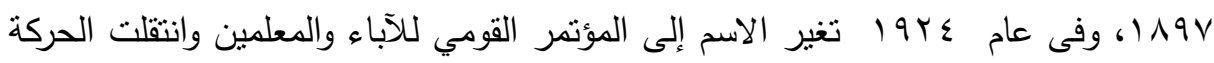

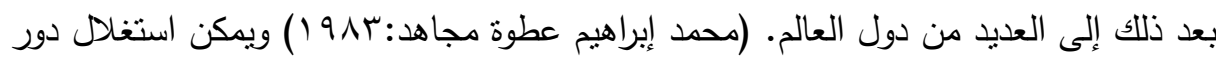

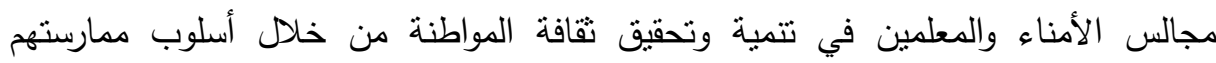

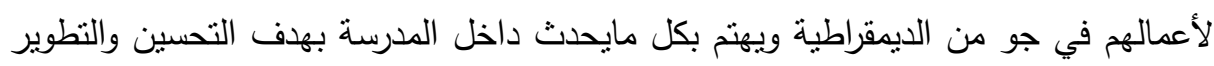
،ويمكن لمجالس الأمناء والمعلمين ان تكون أداة فعالة في رعاية وحماية ثقافة المواطنة داخل

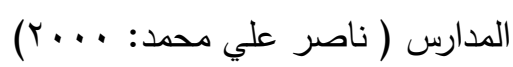

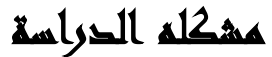

على الرغم من اهمية مجالس الامناء والمعلمين في توثيق التعاون بين الاسرة والمدرسة،

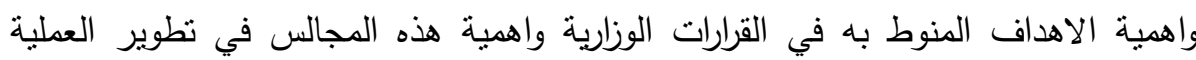


التعليمية الا ان احدا لا يشعر بوجود هذه المجالس وتعتبر صوريا في الواقع الفعلي وان هذه

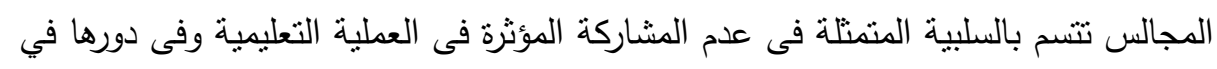

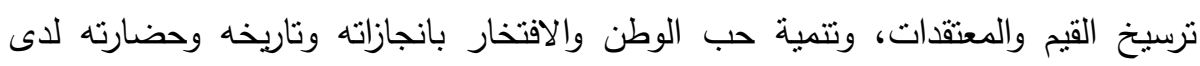
الطلاب وخاصة ان هناك بعض الدارسات التي تثير الى ان مجالس الامناء والمعلمين

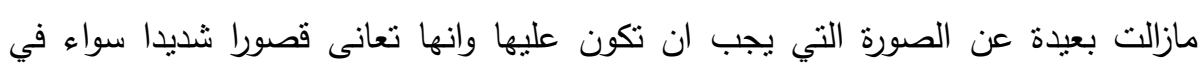

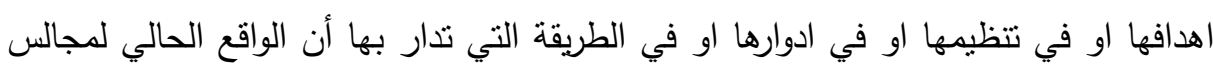



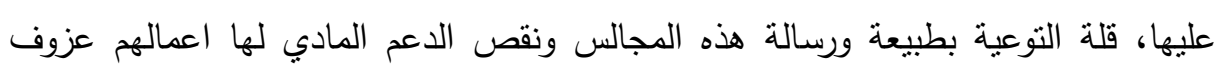

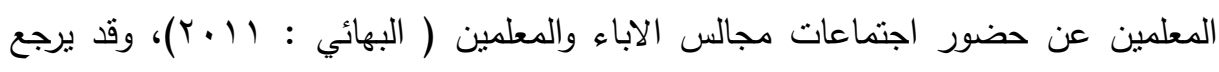
عزوف الاباء الى عدم الأنضمام لهذه المجالس بسبب عدم درايتهم بوجود منل هذه المجالس الاباء

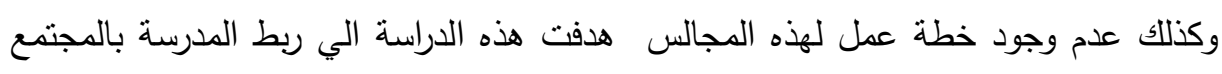
المحيط وبناء مشاركة بينهما مع توضيح بعض الخصائص التي تتضمن مشاركة فعالة ومؤثرة بين المدرسة والمجتمع المحيط حيث تقع فاعلية هذه المشاركة عائق علي كل من قائد المدرسة

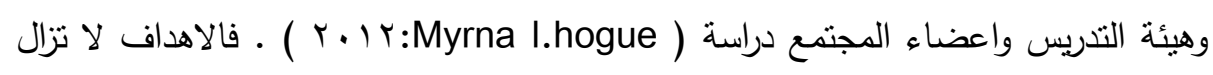

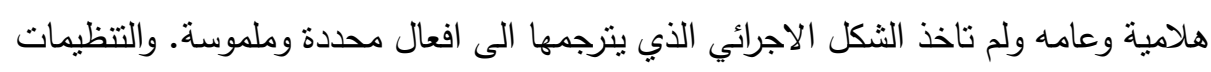
تعانى من قصور نوعية المشتركين فيها وضعف دوافعهم وعدم وضوح اختصاصاتهم وادوارهم

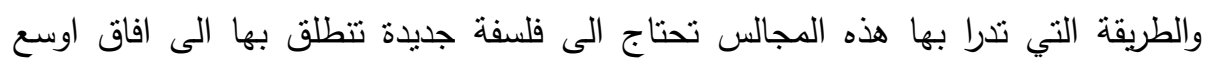
ونشاطات اكثر تتوعا وادوارا اكثر فاعلية في مجال ربط المدرسة بالمجتمع المحلى وعجزها

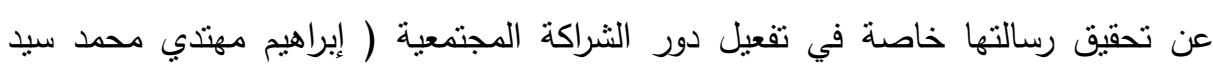

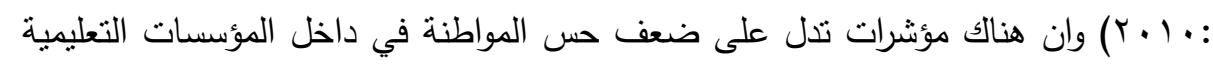

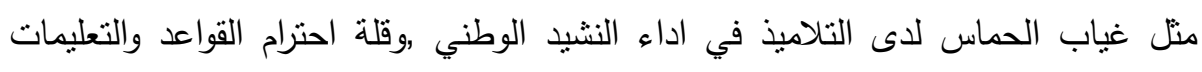



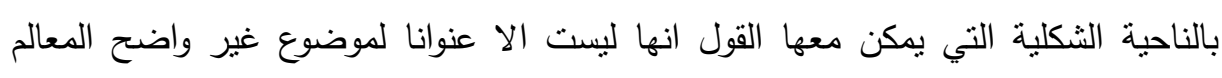

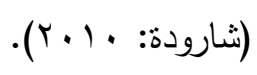




\section{تحساولاهي التراسما}

في ضوء ما سبق يمكن تحديد مشكلة الدراسة في التساؤل الرئيسي التالي: ما دور مجالس الامناء والاباء والمعلمين في تحقيق قيم المواطنة لدى طلاب المرحلة الثانوية؟ ويتفرع من هذا السؤال الرئيس عدد من الاسئلة الفرعية تتمثل في:

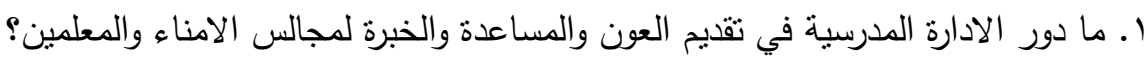
r. ما الادوار التي يقوم بها الاخصائي الاجتماعي داخل مجلس الامناء والمعلمين؟

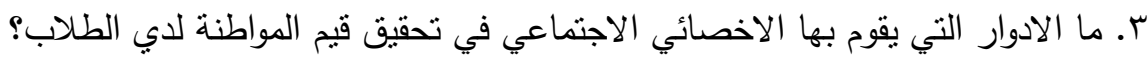
؟. ما دور مجلس الامناء والمعلمين بدورهم في تحقيق قيم المواطنة لدي الطلاب ؟ مالهي

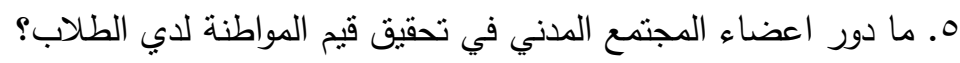

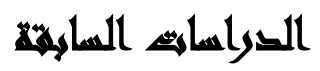

تعد الدراسات والبحوث السابقة المرتبطة بمجال الدراسة وذلك باعتبار انها خطوة هامة

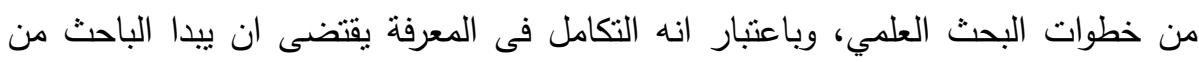
حيث انتهى الاخرون، وتتنتمل الدراسات والبحوث السابقة علي الدحاور الثلاثة التالية: أولاً: الاراسات المتعلقة بمجالس الامناء والاباء والمعلمين: 1- دراسة امينة فاروق محمود شارودة (2010) : مشكلات مجالس الامناء والاباء والمعلمين ومواجهتها باستخدام اسلوب حوكمة المدرسة في ضوء خبرات بعض الدول. هدفت الإراسة المى: ومان: • التعرف على مرتكزات اسلوب الحوكمة والمعايير التي تستعليها مجالس الامناء والاباء والمعلمين. • التعرف على خبرات بعض الدول التي امتتعت باسلوب الحوكمة في مجال مجالس الامناء والاباء والمعلمين. 
•التعرف على الواقع الراهن لدور مجالس الامناء والاباء والمعلمين في مدارس التعليم

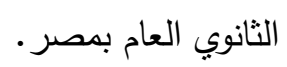

$$
\text { اعتمدت الدراسة على استخدام المنهج المقارن. }
$$

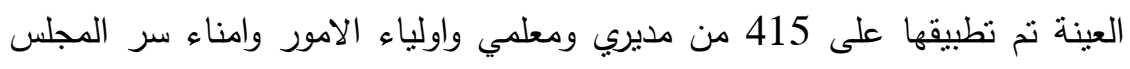
بالمدارس الثانوية العامة بمحافظة القليوبية. توصلت الى وضع توصيات ملئي مقترحة لتفعيل

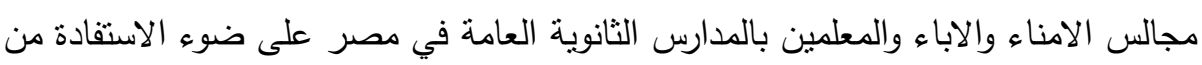

$$
\text { خبرات امريكا وانجلترا واستراليا في مجال حوكمة المدرسة. }
$$

r-دراسة عبير امام مطر صيام (11 + ب): تفعيل مجالس الامناء والاباء والمعلمين بالتعليم

$$
\text { الابتدائي بمحافظة شمال سيناء }
$$

هافت الدراسة الى تفعيل مجالس الامناء والاباء والمعلمين بالتعليم الابتدائي بمحافظة شمال

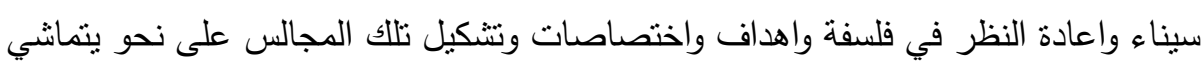
مع طبيعة الحياة والمجتمع السيناوي مما يستدعي تكثيف الجهود المبذولة لتطوير اداء تلك ولكي المجالس للوصول الى تحسين وتطوير وعلاج ما يعوقها بالتعليم الابتدائي بمحافظة شمال

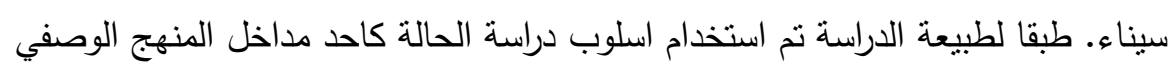

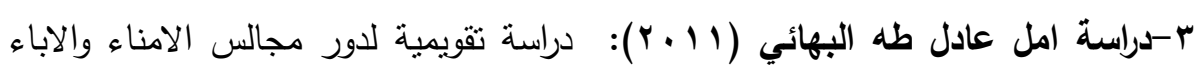

والمعلمين بالمدارس الابتدائية في محافظة بورسعيد في ضوء البهائ القرارات الوزارية.

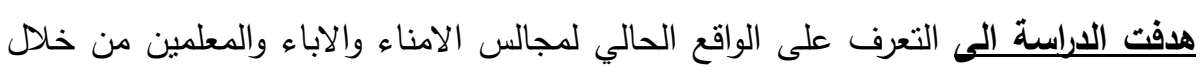

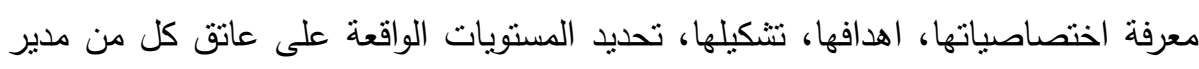

$$
\text { المدرسة، مجلس الامناء الاخصائي الاجتماعي، الرئيس، الأمين. }
$$

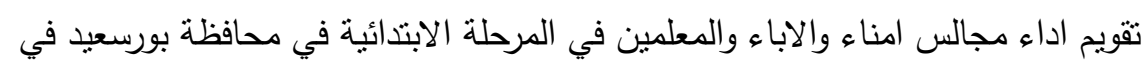

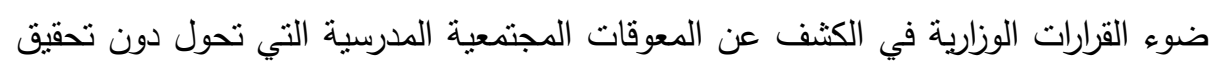
دور فعال لمجالس الامناء والاباء والمعلمين ودورها في ضوء القوات القرارات الوزارية.

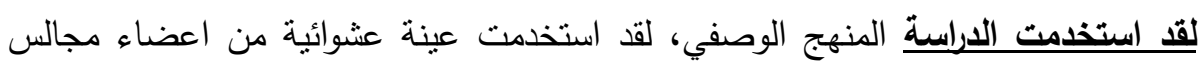
الامناء والاباء والمعلمين بمحافظة بورسعيد وعددهم .(224) 


\section{النتائج توصلت الاراسة الى النتائج التالية:}

• غياب الفهم الواضح لمفهوم اللامركزية في التعليم لدى كثير من القيادات التعليمية ومديري المدارس.

• ضعف وعي اولياء الامور باهمية الدور الذي يلعبه مجالس الامناء والاباء ويرجع ذلك لعدم توفير وسائل الاعلام والمسئولين بالوزارة بالدعاية الكافية. • • اعتقاد الاباء بان ابناءهم وتربيتهم مسئولية المدرسة وحدها.

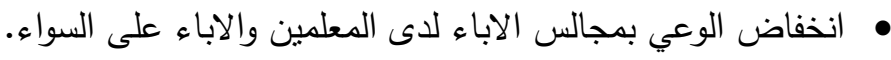

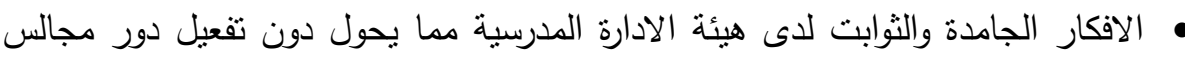
الامناء. צ - دراسة :هبة محمد ابراهيم محمد (10 ـ ب): الاتجاهات البينية لدى اعضاء مجالس امناء التعليم وعلاقتها بتفعيل الانشطة البيئية بمدارس المرحلة الاعدادية. • التعرف على الاتجاهات البينية لدى اعضاء مجالس امناء التعليم بمدارس المرحلة

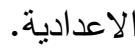
•التعرف على دور مجالس امناء التعليم في تفعيل الانشطة البيئية داخل مدارس المرحلة

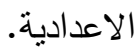
• التعرف على العلاقة بين الاتجاهات البيئية لدى اعضاء مجالس امناء التعليم وتقعيلهم البهات

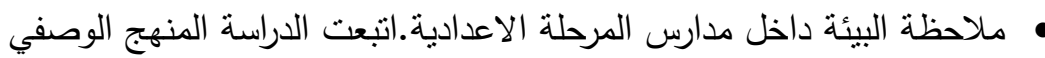
الادوات المستخدمة في الإراسة • تحديد قائمة بالقضايا البيئية التي يجب النية يلم بها اعضاء مجالس امناء التعليم. • • تصميم مقياس اتجاهات بنية لاعضاء مجالس الامناء. • تصميم استنيان لاعضاء مجالس الامناء. العينـة: .9 عضوا من اعضاء مجالس امناء التعليم. 
النتائج توصلت الارلسة الىى النتائج التالبة: توصلت الدراسة من خلال نطبيق مقياس الاتجاهات البيئية على اعضاء مجالس امناء التعليم الى عدم وجود فروق ذات دلالة احصائية بين نتائج المدارس التابعة لادارتي) العجوزة ومصر القديمة التعليمية.

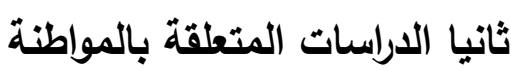

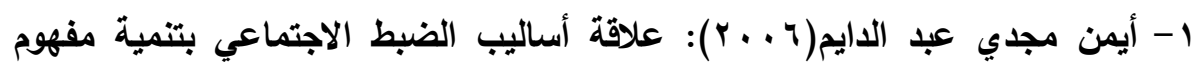
المواطنة

وهدفت هذه الدارسة الى التعرف على السمات الرئيسية التي تتميز بها اساليب الضبط الاجتماعي في مؤسسات التعليم غير النظامي في منطقة البساتين بمحافظة القاهرة في

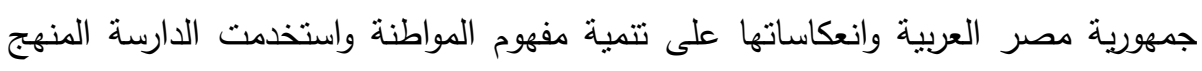

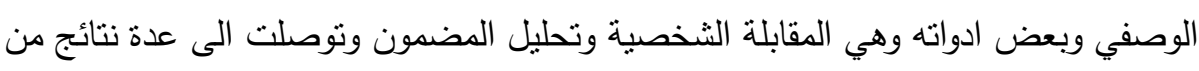
اهمها انه كلما زاد الضبط المؤسسي الممارس على المستئهيدين كلما قلت لديهم المواطنة وقد

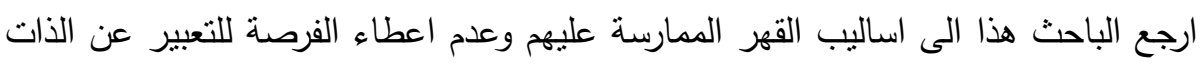

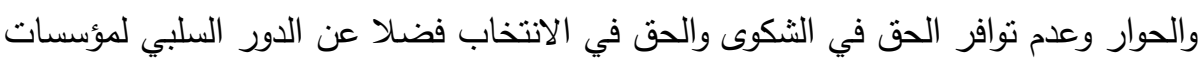

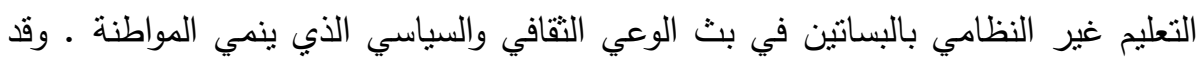
افادت الباحثة من دارسة واقع مؤسسات التعليم غير النظامي ومدى تحقق مفهوم المواطنة فيها ودارسة الاساليب اللاتربوية فيها والتي لا تؤدي الى انتشار ثقافة المئية المواطنة.

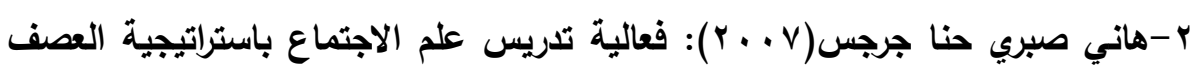

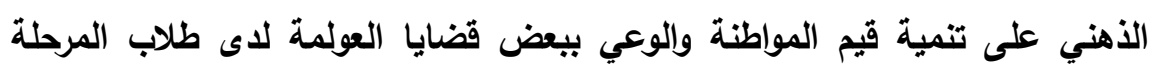
الثانوية

وهدفت الاراسة الى التحقق من فعالية تدريس علم الاجتماع باستراتيجية العصف الذهني على

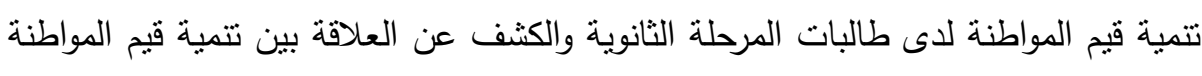
لاى طالبات المرحلة الثانوية ووعيهم ببعض قضايا العولمة واستخدمت الدارسة كل من المنهج الوصفي في تحديد قيم المواطنة وقضايا العولمة التي يهذف البحث الى تتمية وعي الطلاب

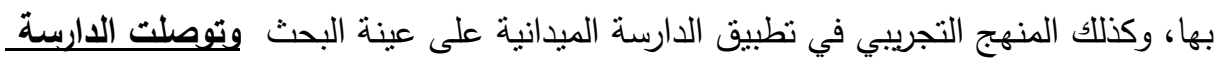

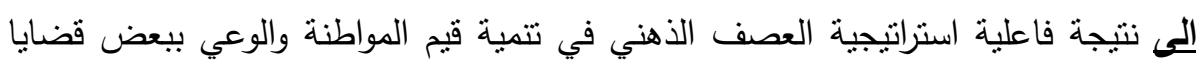

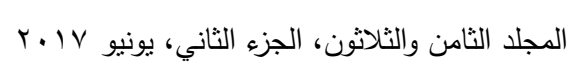


العولمة لدى طالبات المرحلة الثانوية وان مشاركة الطلاب في جلسات العصف الذهني تساهم

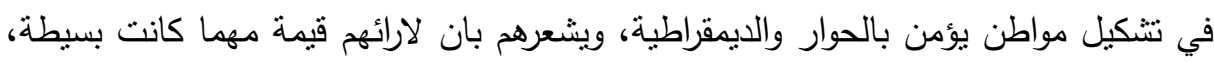
وقد افادت الباحثة من هذه النتائج الني اكدت على دارسة واقع قيمة المواطنة في المرحلة الثانوية وهذا ما انطلق منه البحث الحالي.

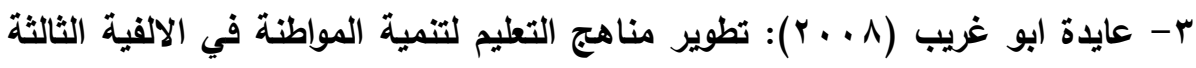
لاى طلاب المرحلة الثانوية

هدفت الدارسة الحيبناء معيار يتضمن ابعاد المواطنة الصالحة الواجب نوافرها في المناهج

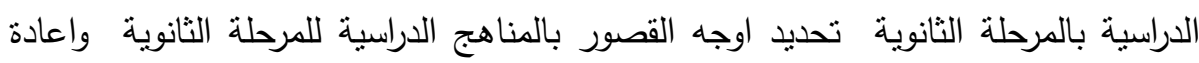

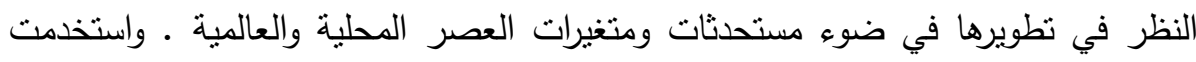
الدارسة المنهج الوصفي لتحليل وتقويم المناهج الدراسية بوضعها الراهن في المرحلة الثانوية ولنية من حيث تتميتها للمواطنة وكذلك المنهج التجريبي من اجل قياس فعالية الحقائق والانشطة التعليمية المقترحة على تتمية المواطنة والتفكير الناقد والقدرة على اتخاذ القرار ـ وتوصلت ولته الدارسة الى ان المناهج الدراسية في المرحلة الثانوية تخلو من المواقف التعليمية الانشطة ولهية التي يمارس الطلاب من خلالها سلوكيات ومهارات المواطنة وذلك من وجهة نظر عينة البحث ان المنهج لا يهيئ للطلاب مواقف يمارسون من خلالها العمل الجماعي ومهارات الاعتماد المتبادل ولا تتمي لدى الطالب تحمل المسؤولية نحو نفسه او مدرسته او مجتمعه كما انها لا لا لهابل

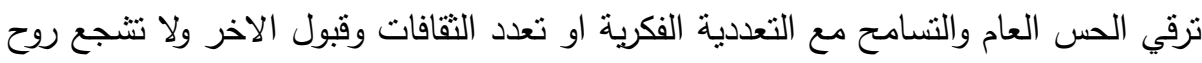

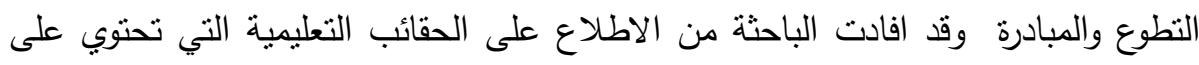
الانشطة التي تهدف الى تتمية المواطنة وتربي لدى الطلاب الثعور بالمسؤولية وتقدير قيم الإطي

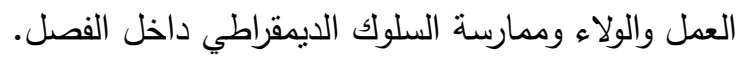




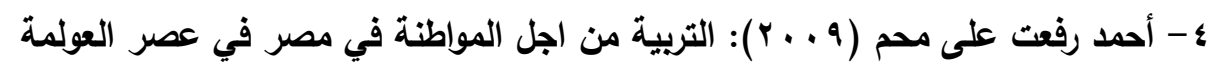
دارسة عبر ثقافية

هافت الدارسة الى تحليل الاسس النظرية المرتبطة بالتربية من اجل المواطنة في عصر

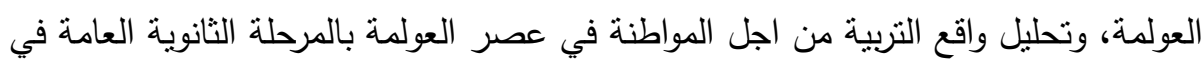

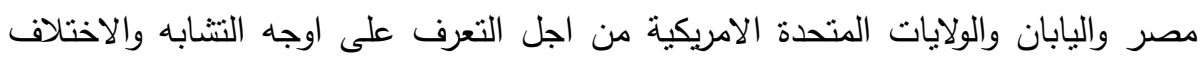

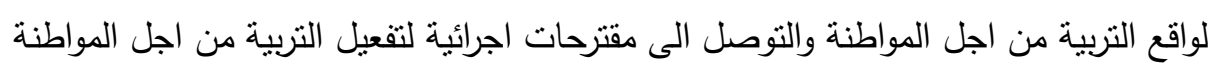
في المرحلة الثانوية العامة في مصر من اجل اعداد مواطن مصري قادر على التى التعامل

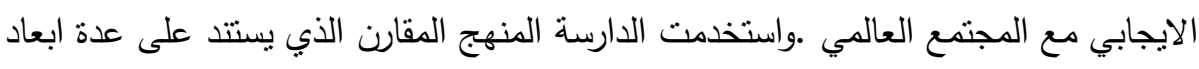
ممثلة في البعد التاريخي، والبعد الوصفي، والبعد التحليلي الثقافي، والبعد المقارن التفسيري .

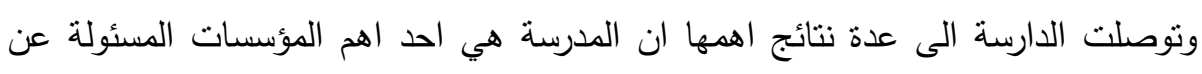

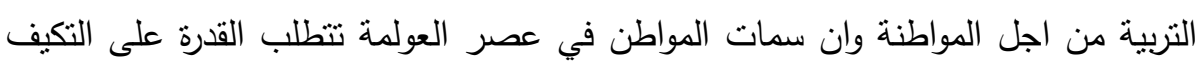
الايجابي مع التغيرات التي قد تؤثر على مجتمعه، والوعي باهمية العدل والمساواة والتسامح

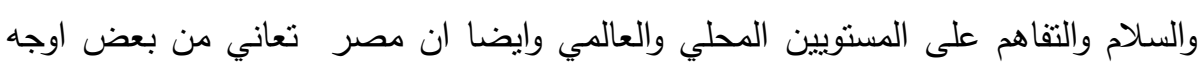

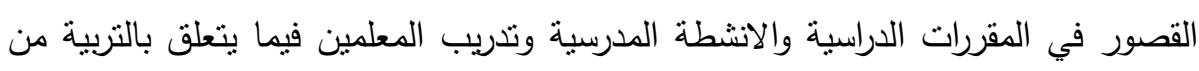

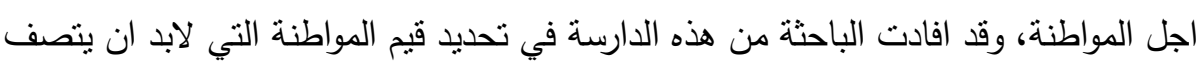

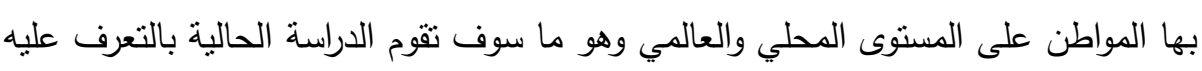
في مجتمع الدارسة.

Mo Kyung Hwan-5

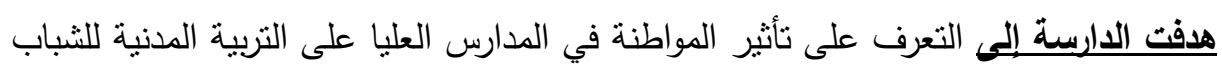
الكوري الأمريكي كما أنها تبحث في الخصائص الديمقارطية العامة لمواطنة الأمريكان الكوريين مقارنة بعناصر عرقية أخرى خاصة المجم وعة المسيطرة على الولايات المتحدة الأمريكية وهم البيض، وهذه الدارسة الاثثوجارفية استمرت لمدة ثلاث سنوات على على الطلاب

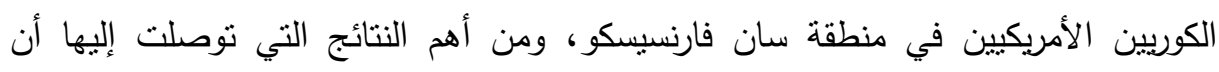

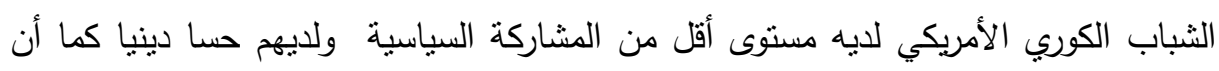

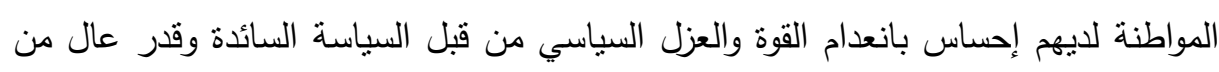

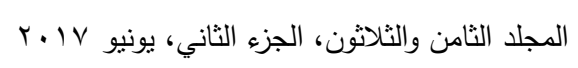


النقة في النظام والقائمين عليه ومن القيم التي يؤمنون بها الاستسلام والرضوخ والآارء الجاهزة التي تدعم الوضع الارهن، أما غيرهم من البيض الأمريكان فقد ظهر أن لديهم توجهات نحو لنه

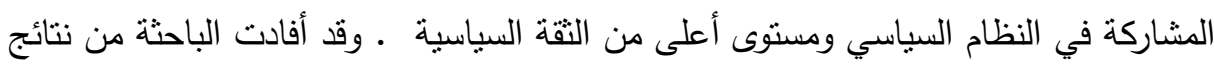

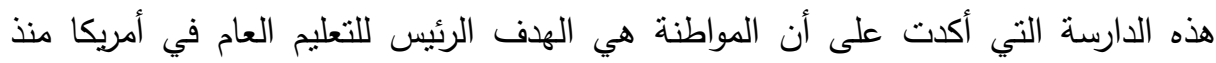

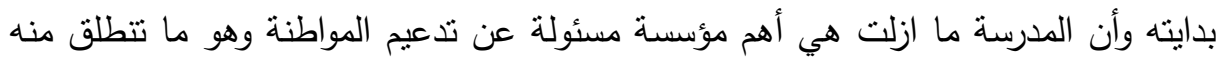
الدارسة الحالية، بالإضافة إلى التعرف على القيم التي تهام المواطنة لدى الثباب وكيفية معالجنها.

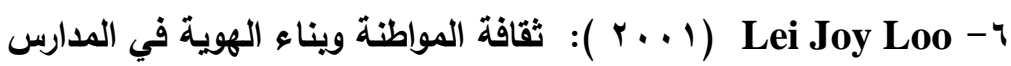
هدفت هذه الدارسة إلى التعرف على العلاقة بين الاختلاف العرقي وبين ثقافة المواطنة وبناء الهوية ـ واعتمدت على المنهج الاثثوجارفي في دارسة مدرسة ثانوية بها طلاب مختلفين عرقيا

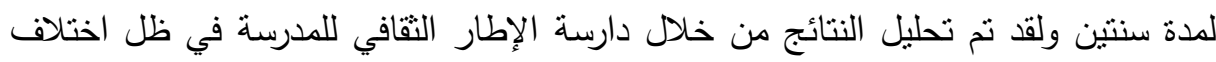

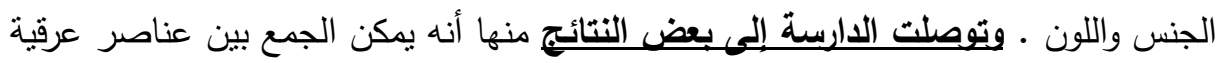
مختلفة من الطلاب بشكل طبيعي في إطار مفهوم ثقافة المواطنة، كما أن الطلاب الذين تم

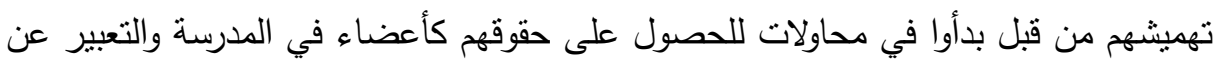
ذواتهم وهويتهم حتى ولو لم يغير هذا في ثقافة المدرسة السائدة .

\section{أهساهث الصواسلة}

\section{تفيد هذه الدراسة في:}

• • التعرف على دور مجالس الامناء والاباء والمعلمين في تحقيق قيم المواطنة • التعرف على مجالات المشاركة بين المؤسسات التربوية منل الاسرة والمدرسة باعتبار هما من أهم المؤسسات التربوية في حياة الفرد • التعرف على اهم قيم المواطنة التي ينبغي ان تتميها مجالس الامناء والاباء والمعلمين • • طرح مقترحات تعين مجالس الامناء والاباء والمعلمين على تتمية قيم المواطنة 


\section{أهمه الصواسمة}

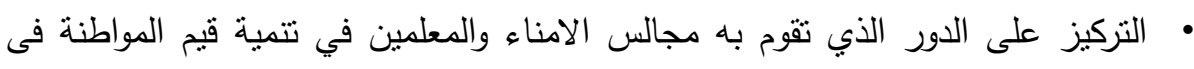

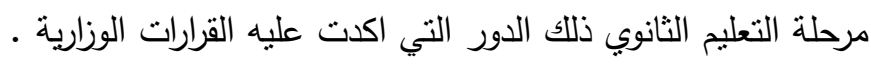
• ان البحث الحالي يسلط الضوء على قضية مهمة في المجتمع وهى المواطنة باعتبارها العنصر الرئيسي فى خلق تتمية شامله في ظل مجتمع ديمقراطي .

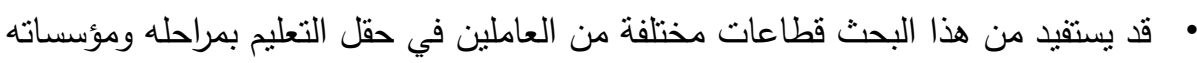
المختلفة.

\section{منهمبية التوراسة}

استخدمت الدراسة الحالية منهج المسح الاجتماعي للتعرف على الواقع الفعلي لدور مجالس الامناء والمعلمين في تحقيق قيم المواطنة، كما اعتمدت على المنهج الوصفي، الذي الذي


اهدافه ,وذلك بالرجوع الى ادبيات التربية والدارسات ذات الصلة بالموضوع وتحليلها، كما ان

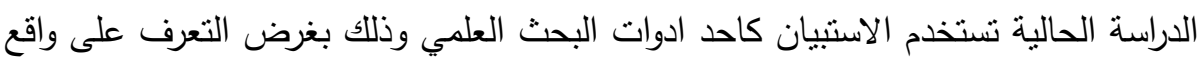

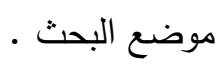

\section{مخاهيه الدراسمة}

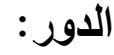

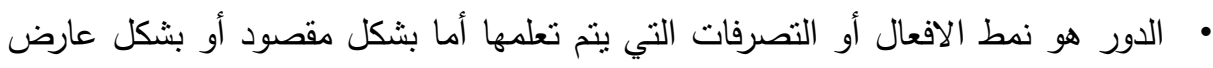

والتي يقوم بها شخص ما في موقف يتضمن تفاعلاً " تيودر ساربن " Teoder. Sarbin

(190乏)"

• الدور هو مجموعة من الأفعال والواجبات التي يتوقعها المجتمع ( ممثلا في هيئاته وأفراده)

فيمن يشغل وضع اجتماعي معين في وقت معين ( سنية خليل " ب ا ـ r).

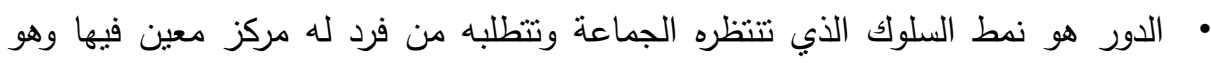

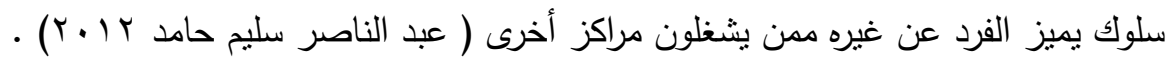


• هو مجموعة من الانشطة المرتبطة واطر سلوكية التي تحقق ما هو متوقع في مواقف

seve

• يعرف الدور بانه اطار معياري للسلوك بطالب به الفرد نتيجة اشتراكه في علاقة وظيفية

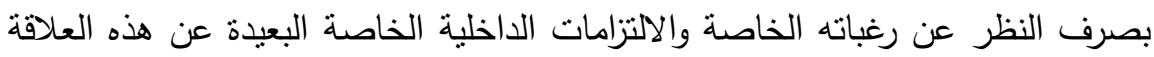
الوظيفية ويتحدد محتوى الدور بمتطلبات الواجبات الوظيفية والنظام الهرمي وتتميز الادوار

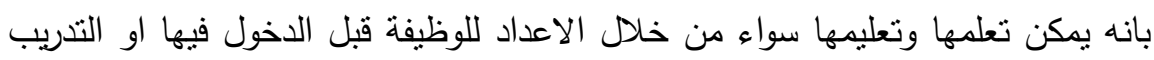
عليها اثثاء ممارستها وكثثر من الادوار يمكن تعلمها عن طريق الملاحظة والتقليد



\section{مجالس الامناء والاباء والمعلمين:}

• تتظيم مدرسي اجتماعي اساسي يعمل على تتشيط الحياة المدرسية ورفع مستوى فاعليتها في ايجاد جيل صالح يكون عماد المجتمع في المستقبل القريب وهو من المنظمات الاساسية الاجتماعية التي تعمل علي نتشيط الحياة المدرسية ورفع مستوى فاعليتها في خلق جيل جديد صالح (سلوى عثمان، سمير حسن: 0. . . ب) • كيان من مجموعه منظمة من الاقراد ممن تتوافر لايهم مسؤوليات جماعية للتخطيط والتصميم والاشراف والمراقبة والتوجيه واتخاذ القرارات داخل المدرسة لصالح العملية

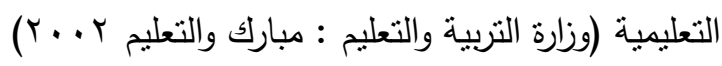
• تتظيم يعمل من اجل تحقيق اهداف المدرسة وتتفيذ خططها وبرامجها داخل وخارج المدرسة وبما يساعد على زيادة انتاجها فمن خلالها تتاح الفرصة لمشاركة كل من اولياء امور التلاميذ وافراد المجتمع المحلى في ادارة المدرسة وهى وسيلة من وسائل الاتصال الفعالة بين المدرسة والبيت واعضاء المجتمع المحلى.

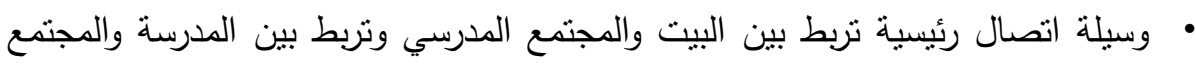

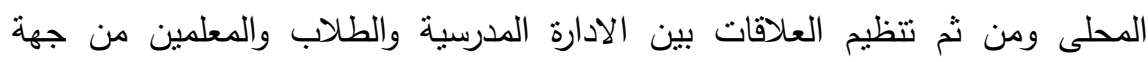

$$
\text { والمجتمع المحلى من جهة اخرى. (نبيل عبد الهادي : ب . . r) }
$$




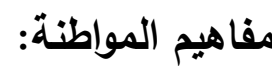

• المواطنة في القران الكريم قال اله تعالي" لقد نصركم اله في مواطن كثيرة (سورة التوبة (ro آلية:



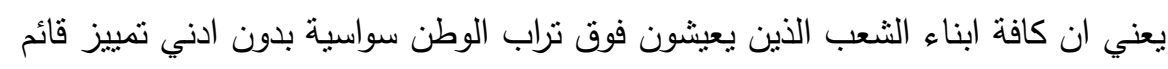

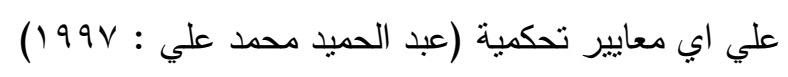

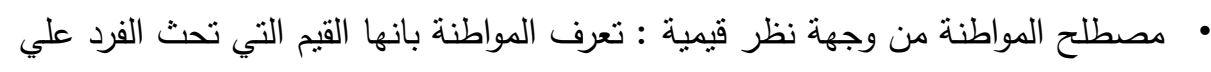

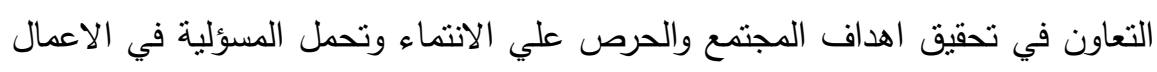

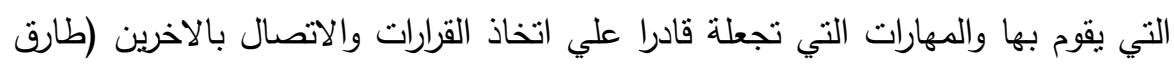

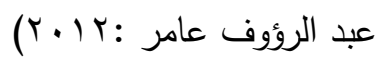
• الدكانة التي تيسر الحصول علي الحقوق الاهلية والحقوق الساسية والاجتماعية والاقتصادية • الثخص الذي له حقوق التصويت وتولي المسؤليات السياسية والتنتع بالسساواة امام

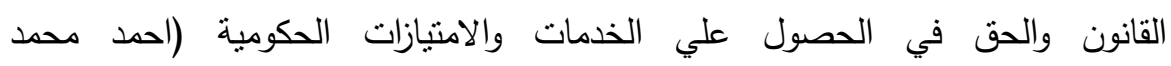
رجائي:r)

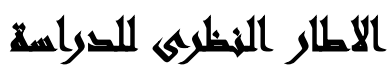

النظريات الاجتماعية وإلنفسية المفسرة للاراسة: هناك العديد من النظريات والمداخل

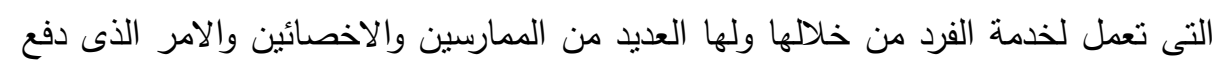

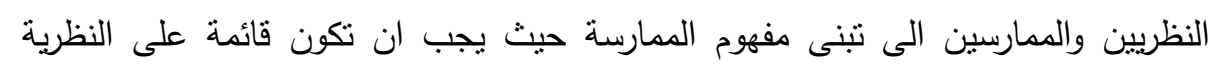

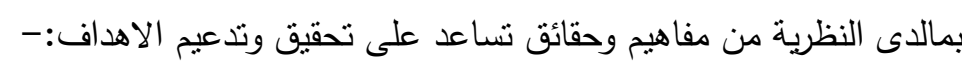

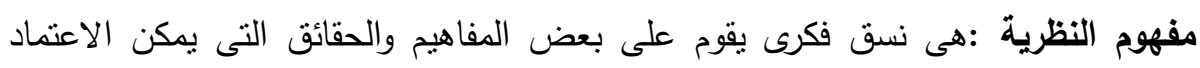
والتاكد من صحتها عن طريق العمل ميدانيا. 
تعريف تالكوت بارسونز :لايرى ان النظرية مستمد او مستتد الى المعطيات الواقعية بل هى نوع

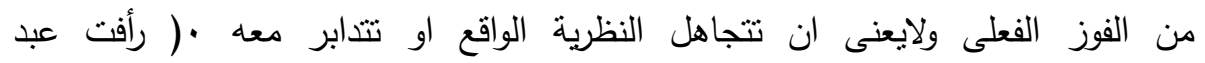

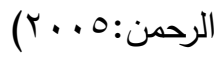

نظريات البنائية الوظيفية: الاتجاهات الوظيفية في جملتها تعبر عن نموذج دراسي نم اشتقاقة عند استخدام الممانلة بين المجتمعات الانسانية والكائنات البشرية وهو يركز علي دوافع الفاعل الانسان في الموقف وهو يعد نموذجا ذاتيا اذ يفهم السلوك في نطاق معناه الذاتي لني عند الفاعل فالافراد من وجهة نظر البنائيين الوظيفين يمارسون انواعا شتي من الافعال واثثاء ادائهم يتبادلون العلاقات الاجتماعية فلا بد لهم من وجود انواع اخري من النشاطات الجزئية التي تكون هادفة الي الحفاظ علي الكل اي ابناء المجتمع الذي توجد فيه ومن خلاله وهذا هو المعني التقريبى المنفق عليه للوظيفة حيث هي الدور الذي يؤدية الجزء في الحياة الاجتماعية وفي الكل الاجتماعي الذي هو البناء والذي يتالف من اجزاء او انساق اجتماعية تتوافق فيما بينها يقصد بالبناء الاجتماعي مجموعة العلاقات الاجتماعية المتباينة التي

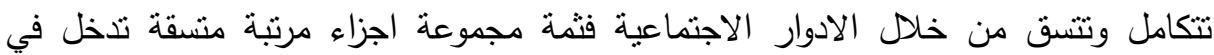
تشكيل الكل وتتحد بالاشخاص والرمز والجماعات وماينتج عنها من علاقات وفقا لادوارها

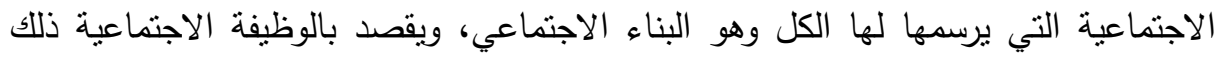
الدور الذي يسهم بت الجزء في الكل هذا هو القدر المتفق عليه بين انصار الاتجاه، كان تركيز الرواد علي البناء الاجتماعي اقوي واوضح من التركيز علي الوظيفة وصور البناء

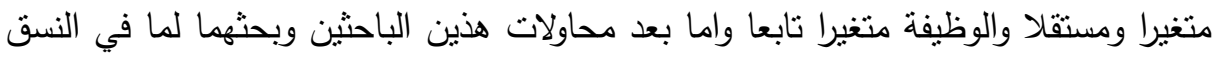

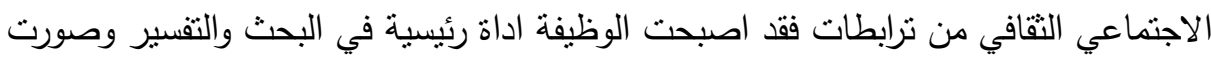
كما لو كانت متغيرا مستقلا (عبد الباسط عبد المعطي : (191). 
نظرية سكنر السلوكية التعليمية فى الثخصية: اهتمام سكنلر كان منصبا على الثى التحليل التجريبى للسلوك وقد ترجع سكنر الدسئولية فى تصرفات الانسان الى الظروف اليبئة

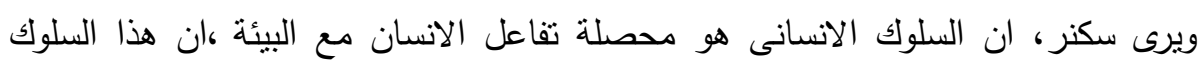

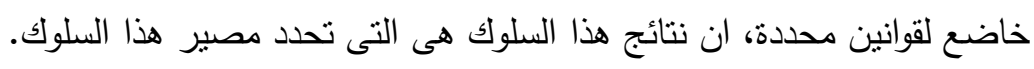

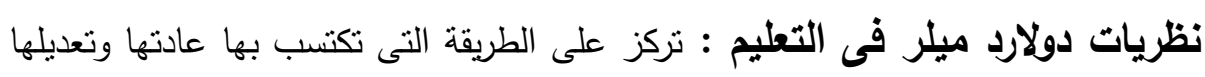

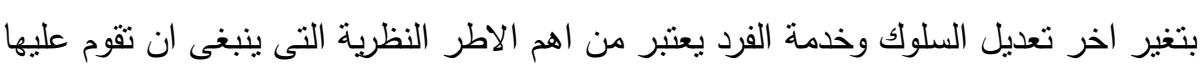

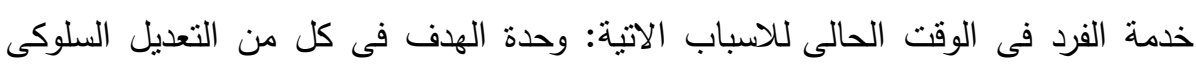

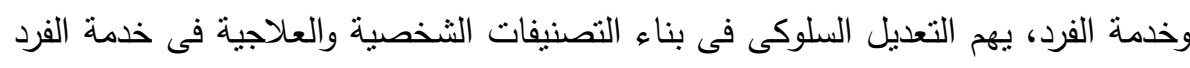

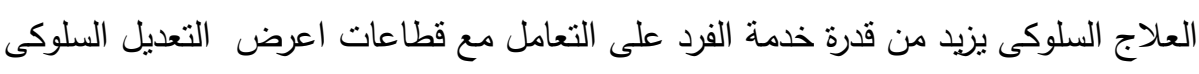

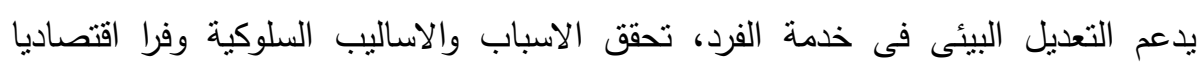

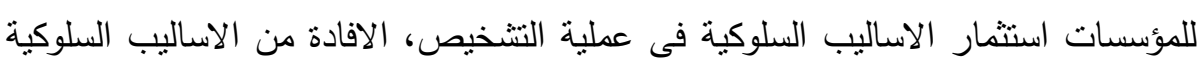



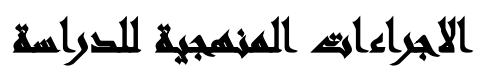

1- نوع الدراسة: تعتبر الدراسة من الدراسات الوصفية التحليلة لانها انسب انواع الدراسات

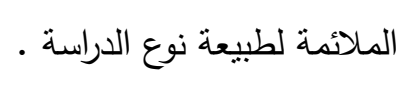

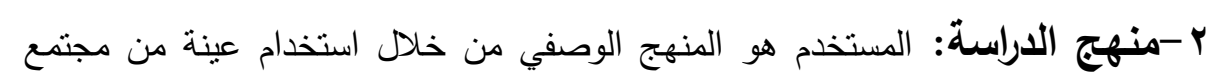



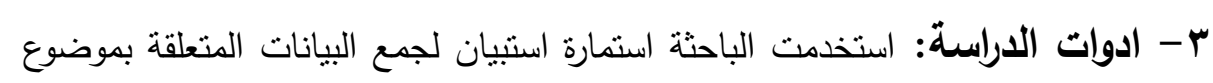
دور مجالس الامناء والمعلمين في تحقيق قيم المواطنة.

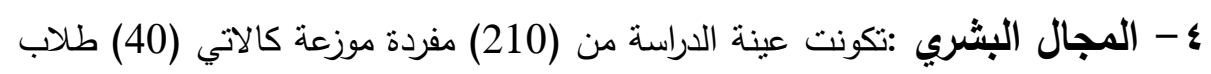

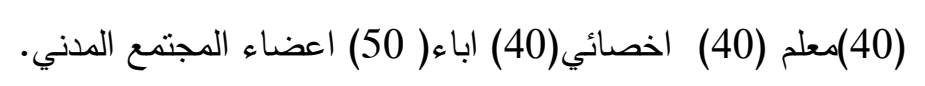

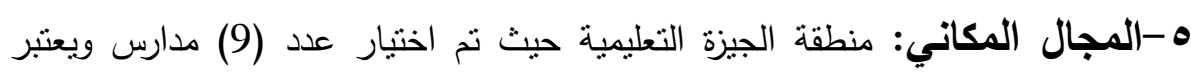

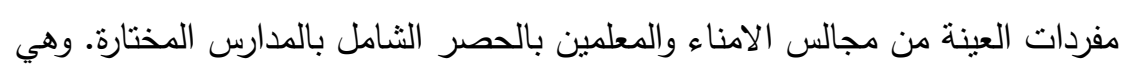

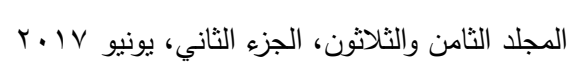


جدول( (): المدارس المختارة بمحافظة الجيزة (منطقة جنوب الجيزة التعليمية)

\begin{tabular}{|c|c|c|}
\hline الموقُع & المدارس المختارة & p \\
\hline العمرانية -الجيزة & مدرسة المنار الحديثة للغات & 1 \\
\hline العمرانية - الجيزة & مدرسة المستقبل الخاصة & $r$ \\
\hline العمرانية -الجيزة & مدرسة الجيزة الكهربائية & $\mu$ \\
\hline العمرانية -الجيزة & مدرسة الهرم الثنانوي العام & $\varepsilon$ \\
\hline العمرانية -الجيزة & مدرسة الثهيد اسامة احمد محمد & 0 \\
\hline العمرانية -الجيزة & مدرسة الجيزة الثانوية & 7 \\
\hline كرداسة - جيزة & مدرسة الاورمان الفندقية & $\mathrm{V}$ \\
\hline الاققى - الجيزة & مدرسة الاورمان الرسمية للغات & $\Lambda$ \\
\hline الهرم - الجيزة & مدرسة الجيزة الزراعية المشتركة & 9 \\
\hline
\end{tabular}

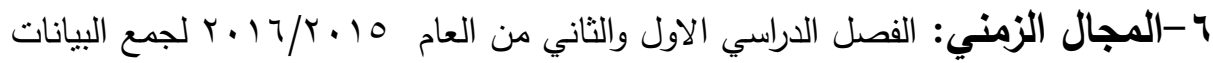

المرتبطة بالدراسة.

- Vروط العينة: قد اخذت الباخثة عينة عمدية مقصودة عشوائية منتظمة ( من الامناء

والمعلمين والاخصائيين والاباء ) وقد راعت الدراسة الثروط التالية:


* ان تشتمل العينة علي طلاب الثانوي العام وفقا لأنواع المدراس المختلفة. * ان تشنمل العينة علي طلاب مدارس وفقا للوزن النسبي لكل مدرسة بمنطقة الدراسة

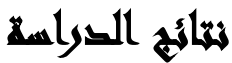

جدول(ץ): المدارس المختارة

\begin{tabular}{|c|c|c|}
\hline$\%$ & العدد & المدارس المختارة \\
\hline$r \cdot, 90$ & $\varepsilon \varepsilon$ & ثانوي عام \\
\hline $1 \cdot, 90$ & $\overline{Y T}$ & زراعي \\
\hline $9,0 Y$ & r. & فندقى \\
\hline $11,9$. & ro & ثانوي عام تجريبي \\
\hline $10, Y \xi$ & rr & ثانوي عام خاص \\
\hline IT, rᄉ & YT & ثانوي صنايع \\
\hline $19, .0$ & $\varepsilon$. & المجتمع المدنى \\
\hline $1 \cdots$ & ri. & الاجمالى \\
\hline
\end{tabular}

292 
جلول(ץ): مجالس الامناء والمعلمين والادارة المدرسية والمهتمين بالعملية التعليمية

\begin{tabular}{|c|c|c|}
\hline$\%$ & العدد & مجالس الامناء \\
\hline $19, .0$ & ह. & الاباء \\
\hline $19, .0$ & $\varepsilon$. & المعلمبن \\
\hline $19, .0$ & $\varepsilon$. & الطلاب \\
\hline $19, .0$ & $\varepsilon$. & اخصائي اجتماعي \\
\hline$r \mu, \Lambda I$ & 0 . & المهتمين \\
\hline $1 \ldots$ & YI. & الاجمالي \\
\hline
\end{tabular}

جدول( ) ): الحالة التعليمية لمفردات العينة

\begin{tabular}{|c|c|c|c|c|c|c|}
\hline \multicolumn{6}{|c|}{ الحالة التعليمية } & \multirow{2}{*}{ الوظيفة } \\
\hline$\%$ & فوق العالى & $\%$ & عالى & $\%$ & متوسط & \\
\hline - & 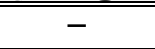 & $\overline{Y T, I Y}$ & $\varepsilon$. & - & 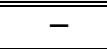 & الاخصائي \\
\hline$r, r_{1}$ & $\varepsilon$ & 17,11 & $r \wedge$ & $\varepsilon, 7 Y$ & $\Lambda$ & الاباء \\
\hline$r, \varepsilon V$ & 7 & 19,70 & $T \varepsilon$ & - & - & المعلمين \\
\hline $1, V T$ & $\mu$ & $r \wedge, q$. & 0. & - & - & المجتمع \\
\hline$V, 01$ & $\pi$ & $\lambda \vee, \wedge T$ & $10 Y$ & $\varepsilon, 7 Y$ & $\Lambda$ & الاجمالح \\
\hline
\end{tabular}

التساؤل الاول: ما هو دور الادارة المدرسية في تقديم العون والمساعدة والخبرة لمجالس

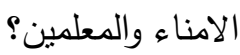

جدول(•): دور الادارة المدرسية في تقديم العون والمساعدة والخبرة لمجالس الامناء والمعلمين

\begin{tabular}{|c|c|c|c|c|}
\hline 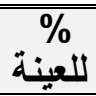 & $\begin{array}{c}\% \\
\% \\
\end{array}$ & التكرار & الادوار & p \\
\hline 00 & I r, vo & r &  & 1 \\
\hline 10 & YI, Vo & rs & للحدرسة الادارة المدرسية الاحتياجات الضرورية اللازمة & $r$ \\
\hline Vo & $1 \wedge, \vee 0$ & r. & البرامج التطوعية. التدرسية نظام يشجع على المشاركة فى & r \\
\hline 7. & 10 & rz & اتخخاذ القرار وتحمل المسؤلية نظّة المدجع على المشاركة فى & $\varepsilon$ \\
\hline 70 & $17, r_{0}$ & $r T$ & الافركانيات البشرية بارلمدية المدرسة. & 0 \\
\hline 7. & 10 & Y & 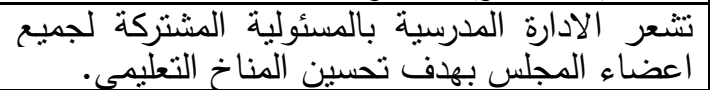 & 7 \\
\hline- & $1 \ldots$ & 17. & الاجمالي & \\
\hline
\end{tabular}

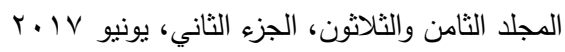


وصف الجدول: قامت الباحثون باستخراج التكرارات والنسب المئوية للفقرات المتعلقة بدور الادارة المدرسية في تقديم العون والمساعدة والخبرة لمجالس الامناء والمعلمين طلاب الثانوي بعينة الدراسة حيث جاءت عبارة( تحرص الادارة المدرسية علي دعوة جميع الامناء والمعلمين

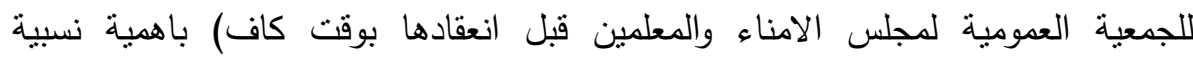

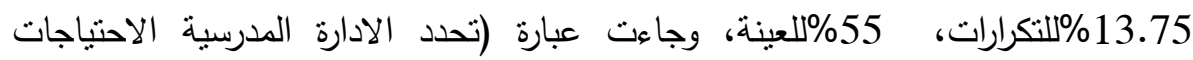
الضرورية اللازمة للمدرسة) باهمية نسبية 21.25\% للتكرارات، 85\% للعينة، وجاءت عبارة (توفر الادارة المدرسية نظام يشجع علي المشاركة في البرامج التطوعية) باهمية نسبية

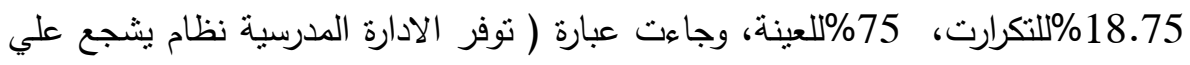

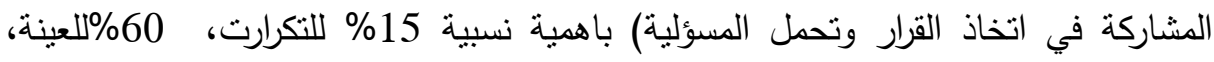
وجاءت عبارة (توفر الادارة المدرسية المعلومات الكافية عن الامكانيات البشرية بالمدرسة) باهية نسبية 16.25\% للتكرارت، 65\% للعينة ،جاءت عبارة (تتعر الادارة المدرسية بالمسئولية المشتركة لجميع اعضاء المجلس بهدف تحسين المناخ التعليمي ) باهمية نسبية 15\% للتكرارت، 60\% للعينة.

وبترتيب الادوار التي تقوم بها الادارة الددرسية في تقديم العون والمساعدة والخبرة لمجالس الامناء والمعلمين تبين ان عبارة (تحدد الادارة المدرسية الاحتياجات الضرورية

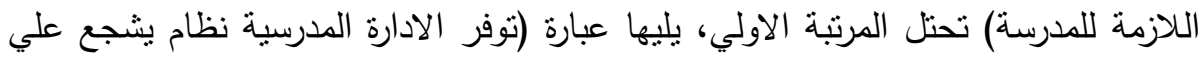

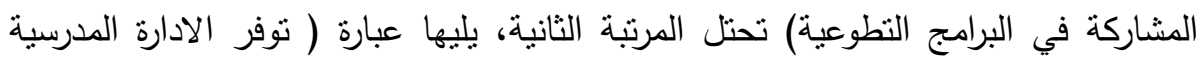

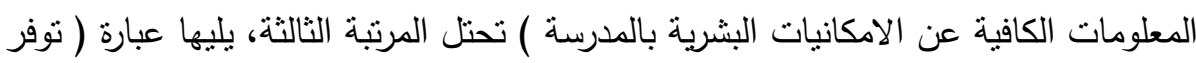
الادارة المدرسية نظام يشجع علي المشاركة في اتخاذ القرار وتحمل المسؤلية،تشعر الادارة المدرسية بالمسئولية المشتركة لجميع اعضاء المجلس بهدف تحسين المناخ التعليمي) تحتل المرنبة الرابعة، يليها عبارة (تحرص الادارة المدرسية علي دعوة جميع الامناء والمعلمين للجمعية العمومية لمجلس الامناء والمعلمين قبل انعقادها بوقت كاف )تحتل المرتبة الخامسة الحته 
تفسير وتحليل الجدول: يتضح من الجدول ان كل العبارات تتعدي اهميتها النسبية الي اكثر

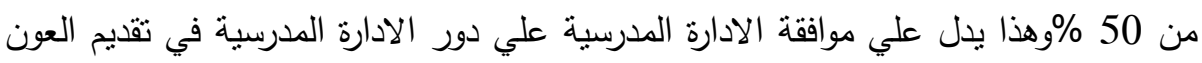

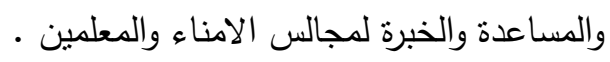

\section{الادوار التي يقوم بها الاخصائي الاجتماعي داخل مجلس الامناء وإلمعلمين}

التساؤل الثاني: ما الادوار التي يقوم بها الاخصائي الاجتماعي داخل مجلس الامناء

والمعلمين؟

جدول(7): الادوار التي يقوم بها الاخصائي الاجتماعي داخل مجلس الامناء والمعلمين

\begin{tabular}{|c|c|c|c|c|}
\hline \% للعينة & $\begin{array}{l}\% \\
\%\end{array}$ & 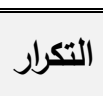 & الادوار & b \\
\hline 9. & Tr,YT & $r 7$ & توثيق العلاقة بين البيت والمدرسة & 1 \\
\hline$r V, 0$ & Q,Tr & 10 & نشتري ثقافي وتربوي طلاب الددرسة وتحقيق اعلي & r \\
\hline$\varepsilon$. & $9,9 \leqslant$ & 17 & 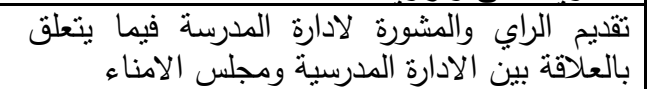 & $r$ \\
\hline$\leqslant 0$ & 11,11 & 11 & تلعميف وتحليل القرارات ذات القوانين والنشرات المبلية المنظيمية & $\varepsilon$ \\
\hline$\leqslant Y, O$ & $1 ., 07$ & IV & تخصاعد العملية التعليمية في الاطلاع علي المستجدات التي & 0 \\
\hline 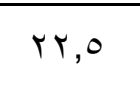 & 0,09 & 9 & القرشارات النتي تد ع العملية التُعليمية فنع واتخاذ وتتفيذ & 7 \\
\hline$\leqslant 0$ & 11,11 & 11 & 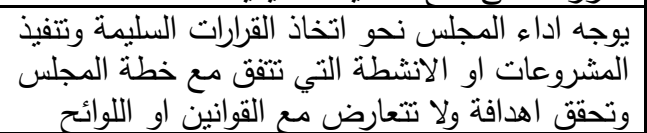 & V \\
\hline A. & $19, \wedge \wedge$ & Tr & 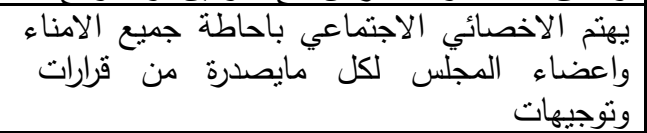 & $\wedge$ \\
\hline $1 \cdots$ & $1 \ldots, \ldots$ & 171 & الاجمالى & \\
\hline
\end{tabular}

وصف الجدول: قامت الباحثون باستخراج التكرارات والنسب المئوية المتعلقة بالادوار التي يقوم

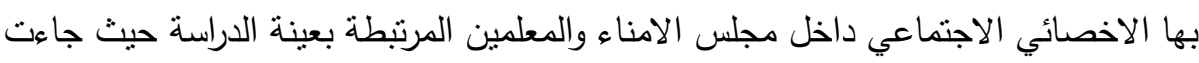


وجاءت عبارة (نشر الوعي بين طلاب المدرسة وتحقيق اعلي مستوي ثقافي وتربوي) باهمية نسبية 9.32 \% للتكرارات، \% 37.5 للعينة ،وجاءت عبارة (تقديم الراي والمشورة لادارة 
المدرسة فيما يتعلق بالعلاقة بين الادارة المدرسية ومجلس الامناء) باهمية نسبية 9.94 \% للتكرارت، 40\%للعينة، وجاءت عبارة (تعريف وتحليل القرارات والقوانين والنشرات المنظمة لاعمال المجلس وايضا ذات الصلة بالعملية التعليمية) باهمية نسبية 11.18\% للتكرارت ،0؛ \%للعينة، وجاءت عبارة ( يساعد المجلس في الاطلاع علي المستجدات التي تخص العملية التعليمية) باهية نسبية10.56\% للتكرارت، 42.5\% للعينة ،جاءت عبارة ( برشد المجلس ويساعدة في صنع واتخاذ وتتفيذ القرارات التي تدع العملية التعليمية ) باهمية نسبية 5.59\% باتهية للتكرارت، 22.5\% للعينة ،وجاءت عبارة ( يوجه اداء المجلس نحو اتخاذ القرارات السليمة

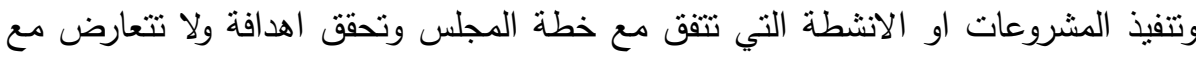
القوانين او اللوائح) باهمية نسبية11.18 \% للتكرارت، 45\% للعينة، وجاءت عبارة (بهتم الاخصائي الاجتماعي باحاطة جميع الامناء واعضاء المجلس لكل مايصدرة من قرارات وتوجيهات) باهمية نسبية 19.88 \% للتكرارت ، 80 \% للعينة. وبترتيب الادوار التي يقوم بها الاخصائي الاجتماعي داخل مجلس الامناء والمعلمين تبين ان عبارة( توثيق العلاقة بين البيت والمدرسة ) تحتل المرتبة الاولي، يليها عبارة ( يهتم الاخصائي الاجتماعي باحاطة جميع الامناء واعضاء المجلس لكل مايصدرة من قرارات وتوجيهات) تحتل المرتبة الثانية، يليها عبارة ( تعريف وتحليل القرارات والقوانين والنشرات التهاء المنظمة لاعمال المجلس وايضا ذات الصلة بالعملية التعليمية، يوجه اداء المجلس نحو اتخاذ القرارات السليمة وتتفيذ المشروعات او الانشطة التي تتفق مع خطة المجلس وتحقق اهدافة ولا

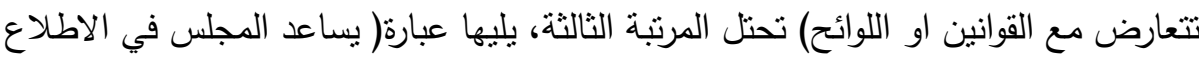
علي المستجدات التي تخص العملية التعليمية) تحتل المرتبة الرابعة، يليها عبارة (تقديم الراي

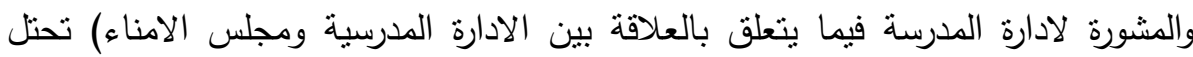
المرتبة الخامسة، يليها عبارة (نشر الوعي بين طلاب المدرسة وتحقيق اعلي مستوي نقافي وتزبوي) تحتل المرتبة السادسة. 
تفسير وتحليل الجدول: يتضح من الجدول ان بعض العبارات تتعدي اهميتها النسبية الي اكثر من 50 \%فيما يتعلق الادوار التي يقوم بها الاخصائي الاجتماعي داخل مجلس الامناء

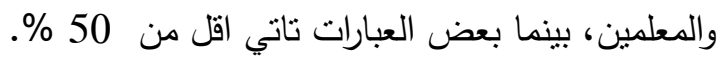

الادوار التي يقوم بها الاخصائي الاجتماعي في تحقيق قيم المواطنة

التساؤل الثالث ما الادوار التي يقوم بها الاخصائي الاجتماعي في تحقيق قيم المواطنة؟ جدول(V): الادوار التي يقوم بها الاخصائي الاجتماعي في تحقيق قيم المواطنة

\begin{tabular}{|c|c|c|c|c|}
\hline 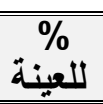 & \begin{tabular}{c|c}
$\%$ \\
\end{tabular} & التكرار & الادوار & b \\
\hline 10 & $Y Y, 9 V$ & $\Gamma \varepsilon$ & 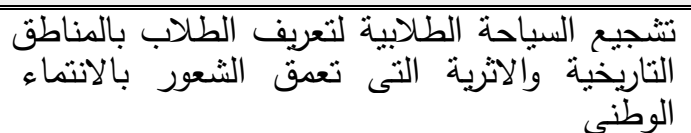 & 1 \\
\hline 9 . & T $\varepsilon, T r$ & rq & 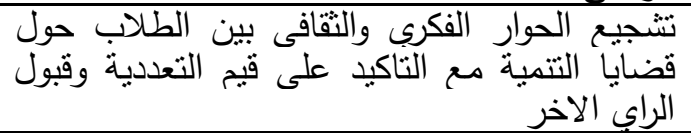 & r \\
\hline 70 & $\mathrm{IV}, \mathrm{OV}$ & Y7 & التدريب على الديمقراطية من خلال برلمان الطلاب & $\mathrm{r}$ \\
\hline vo & $Y \cdot, Y V$ & r. & تشنيعة مساهمة الطلاب فى انشطة الخدمة العامة & $\varepsilon$ \\
\hline 00 & $1 \varepsilon, \wedge 7$ & Tr & نشامة المشافروعات الصنغ الحريزة الطلاب وتشجعيهم على & 0 \\
\hline- & $1 \ldots$ & $1 \leqslant \Lambda$ & 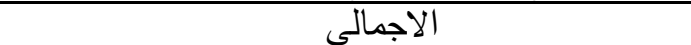 & \\
\hline
\end{tabular}

وصف الجدول: قامت الباحثّن باستخراج التكرارات والنسب المئوية المتعلقة بالادوار التي يقوم

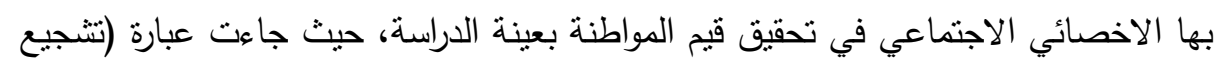
السياحة الطلابية لتعريف الطلاب بالمناطق التاريخية والاثرية التي تعمق الشعور بالانتماء الوطني) باهمية نسبية22.97 \% للتكرارت، 85\% للعينة، وجاءت عبارة ( تشجيع الحوار الفكري والتقافي بين الطلاب حول قضايا التتمية مع التاكيد علي قيم التعددية وقبول الراي

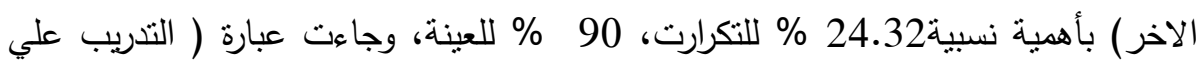
الديمقراطية من خلال برلمان الطلاب )باهمية نسبية 17.57 \% للتكرارت، 65\% للعينة، وجاءت عبارة (تثجيع مساهمة الطلاب في انشطة الخدمة العامة والانشطة التطوعية ) باهمية نسبية20.27 \% للتكرارت، 75\% للعينة، وجاءت عبارة ( نشر ثقافة العمل الحر بين الطلاب

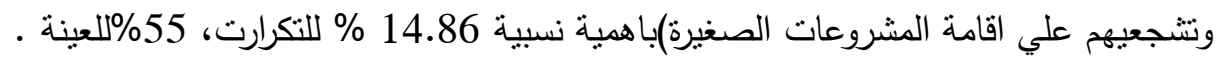

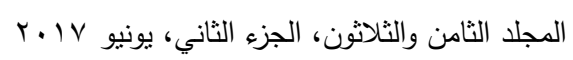


وبترتيب الادوار التي الادوار التي يقوم بها الاخصائي الاجتماعي في تحقيق قيم

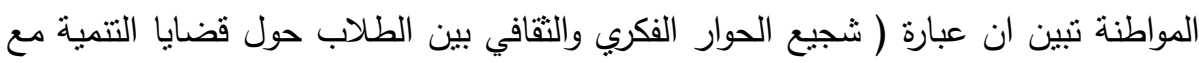

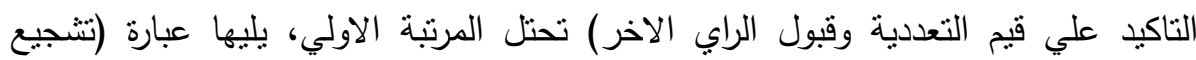
السياحة الطلابية لتعريف الطلاب بالمناطق التاريخية والاثرية التي تعمق الثعور بالانتماء الوطني) تحتل المرتبة الثانية، يليها عبارة (تتجيع مساهمة الطلاب في انثطة الخدمة العامة والانشطة التطوعية )تحتل المرتبة الثالثة، يليها عبارة (التدريب علي الديمقراطية من خلال

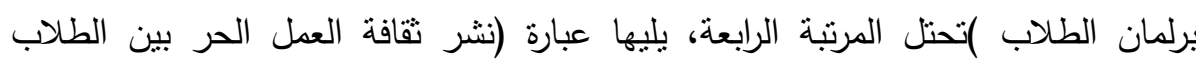
وتتجعيهم علي اقامة المشروعات الصغيرة ) تحتل المرنبة الخامسة. تفسير وتحليل الجدول يتضح من الجدول ان كل العبارات تتعدي اهميتها النسبية الي اكثر من 50 \%فيما يتعلق الادوار التي يقوم بها الاخصائي الاجتماعي في تحقيق قيم المواطنة دور مجلس الامناء والمعلمين بدورهم في تحقيق قيم المواطنة التساؤل الرابع: ما دور مجلس الامناء والمعلمين بدورهم في تحقيق قيم المواطنة؟ جدول(^): دور مجلس الامناء والمعلمين في تحقيق قيم المواطنة

\begin{tabular}{|c|c|c|c|c|}
\hline ل للعينة & $\begin{array}{c}\% \\
\end{array}$ & التكرار & الادوار & p \\
\hline$O V, O$ & $19, \leqslant 9$ & Tr & 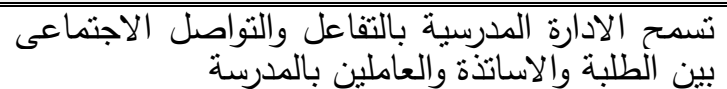 & 1 \\
\hline$O r, O$ & $I V, \Lambda$. & YI & 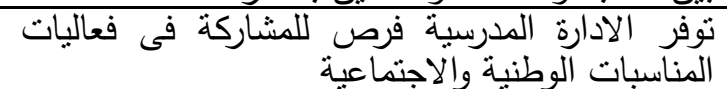 & r \\
\hline$T r, 0$ & $r 1,19$ & ro &  & r \\
\hline$\leqslant Y, O$ & $\mid \varepsilon, \leqslant 1$ & IV & توالتعليمية والادهارة المدربية والسلوكية المناخ لاشباع الحاجات المعرفية & $\varepsilon$ \\
\hline$\Lambda$. & $r V, I T$ & Tr & تلتى ممنلكات المدرسية على تحقيق قيم الامانة والحفاظ & 0 \\
\hline & $1 \ldots$ & 111 & الاجمالى & \\
\hline
\end{tabular}


وصف الجدول: قامت الباحثون باستخراج التكرارات والنسب المئوية المتعلقة بدور مجلس الامناء والمعلمين بدورهم في تحقيق قيم المواطنة المرتبطة بعينة الدراسة حيث جاءت بات عبارة (تسمح الادارة المدرسية بالتفاعل والتواصل الاجتماعي بين الطلبة والاساتذة والعاملين بالمدرسة) باهمية نسبية 19.49\% للتكرارت ، 57.5\%للعينة، وجاءت ولاءت عبارة (توفر الادارة المدرسية فرص للمشاركة في فعاليات المناسبات الوطنية والاجتماعية) باهمبة نسبية 17.80\% للتكرارت ، 52.5\%للعينة ،وجاءت عبارة (تطبق الادارة المدرسية الانظمة واللوائح والقوانين بما يحقق المساواة وتكافؤ الفرص بين جميع الطلبة) باهمية نسبية

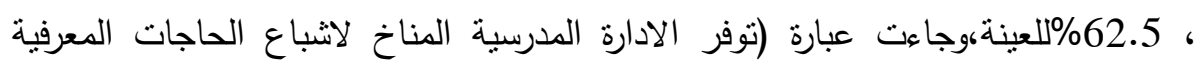

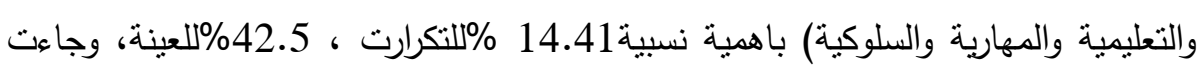

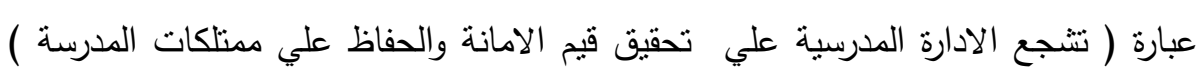
باهمية نسبية 27.12 \% للتكرارت ، 80\% للعينة. وبترتيب الادوار التي دور مجلس الامناء والمعلمين بدورهم في تحقيق قيم المواطنة تنين

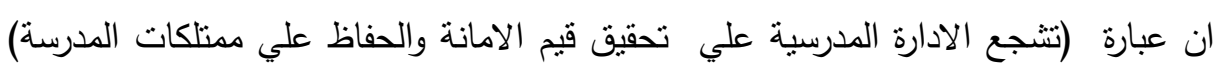
تحتل المرتبة الاولي، يليها عبارة(تطبق الادارة المدرسية الانظمة واللوائح والقوانين بما يحقق الأنق

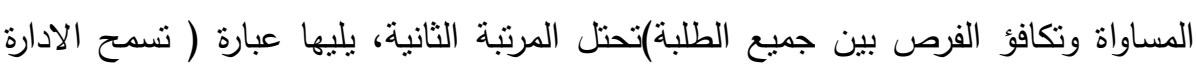

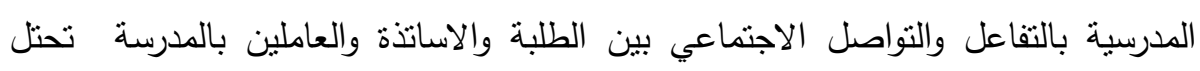

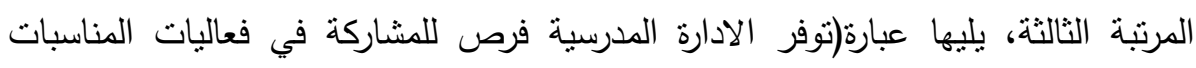

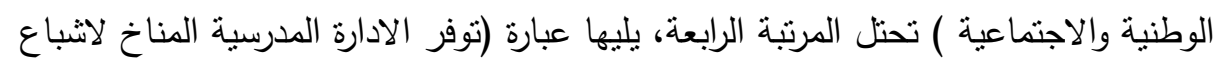
الحاجات المعرفية والتعليمية والمهارية والسلوكية) تحتل المرتبة الخامسة. تفسير وتحليل الجدول يتضح من الجدول ان كل العبارات تتعدي اهميتها النسبية الي اكثر من 50\% فيما يتعلق دور مجلس الامناء والمعلمين بدورهم في تحقيق قيم المواطنة 
دور اعضاء المجتمع المدني في تحقيق قيم المواطنة:

التساؤل الخامس ما دور اعضاء المجتمع المدني في تحقيق قيم المواطنة؟ جدول(9): دور اعضاء المجتمع المدني في تحقيق قيم المواطنة

\begin{tabular}{|c|c|c|c|c|}
\hline ل العينة & ب & 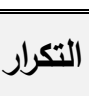 & الادوار & r \\
\hline$\sum 0$ & $1 \leqslant, V_{0}$ & 11 & يشترك اعضاء المجتمع مع المدرسة في وضع خطتها & 1 \\
\hline 00 & $1 \wedge, \cdot r$ & rY & يدرب اعضاء المجتمع على القيام بالمهام المطلوبة & $r$ \\
\hline 0 . & $17, r 9$ & r. & يقدم اعضاء المجتمع على القيام بالمهام المطلوبة & r \\
\hline $\mathrm{v} \cdot$ & $r, 90$ & rA & تلتهلية مشاركة اعضاء المجتمع فى تطوير العملية & $\varepsilon$ \\
\hline$\sum 0$ & $1 \leqslant, V_{0}$ & 11 & يقوم اعضاء المجتمع بمسؤليتهم في المجلس & 0 \\
\hline ๕. & 1111 & 17 & ألمواضيع دعوة اعضاء العلاقة المدافت اللتحدسة حول مختلف & 1 \\
\hline & $1 \cdots$ & MT & 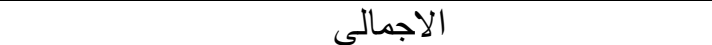 & \\
\hline
\end{tabular}

وصف الجدول: قامت الباحثون باستخراج التكرارات والنسب المئوية المتعلقة بدور اعضاء المجنمع المدني في تحقيق قيم المواطنة المرتبطة بعينة الدراسة حيث جاءت عبارة بارة ( يشترك

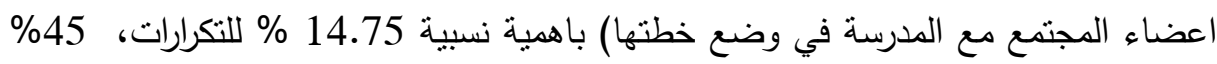
للعينة، وجاءت عبارة (يدرب اعضاء المجتمع علي القيام بالمهام المطلوبة) باهمية نسبية 18.03\% للتكرارت، 55\% 55 للعينة،وجاءت عبارة( يقدم اعضاء المجتمع علي القيام بالمهام المطلوبة ) باهمية نسبية16.39 \% للتكرارت ، 50\%للعينة، وجاءت عبارة ( نسهم مشاركة

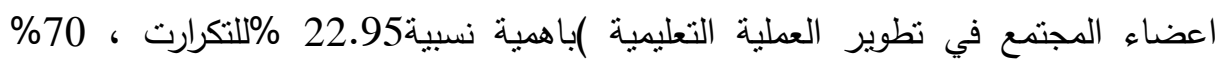
للعينة، وجاءت عبارة ( يقوم اعضاء المجتمع بمسؤليتهم في المجلس )باهمية نسبية

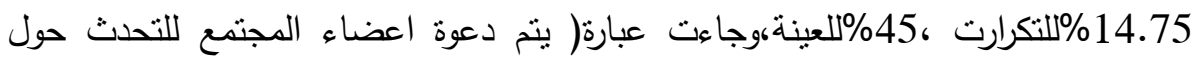



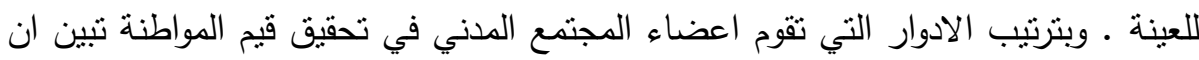

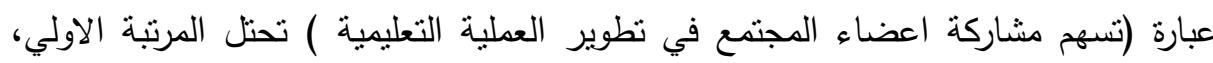
يليها عبارة(يدرب اعضاء المجتمع علي القيام بالمهام المطلوبة)تحتل المرنبة الثانية، يليها 
عبارة(يقدم اعضاء المجتمع علي القيام بالمهام المطلوبة )تحتل المرتبة الثالثة، يليها عبارة(بشترك اعضاء المجتمع مع المدرسة في وضع خطتها،يقوم اعضاء المجتمع بمسؤليتهم

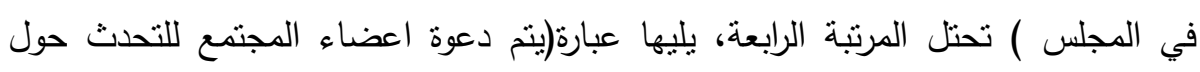

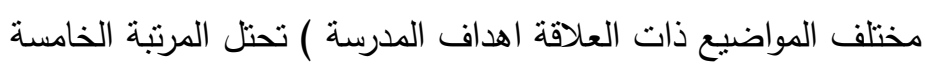
تفسير وتحليل الجدول: يتضح من الجدول ان بعض العبارات تتعدي اهميتها النسبية الي

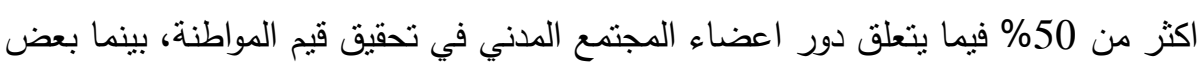

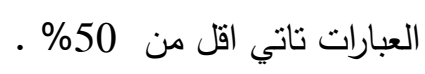
جدول(· (1): تحليل التباين لاراء الاخصائي الاجتماعي ( الاجمالي والفردي من وجهة نظر الاخصائيين وأجمالي العينة)

\begin{tabular}{|c|c|c|}
\hline الاخصائي آجمالى & الاخصائي فزدي & الاستـلال الاحصائى \\
\hline $111,1 \mathrm{CO}^{\prime}$ & $r q, r \vee v$ & المتوسط \\
\hline $1.9 \cdot, 9 \wedge r$ & 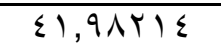 & التباين \\
\hline \multirow[t]{6}{*}{$\Lambda$} & $\wedge$ & المشاهدات آو العبارات \\
\hline & . & ختبار الفروض بين متوسطين \\
\hline & $\Lambda$ & درجات الحرية \\
\hline & $7, \wedge 79 \leq 9-$ & قيمة ت المحسوبة \\
\hline & $7, \leqslant Y E-.0$ & قيمة أقل فرق معنوي \\
\hline & $1,1090 \leqslant 1$ & قيمة ت الجدولية \\
\hline
\end{tabular}

\begin{tabular}{|c|c|c|c|c|}
\hline التباين & متوبط & مجموع & العدد & المجموعات \\
\hline 7 & $\varepsilon, 0$ & דו & $\Lambda$ & البنود \\
\hline \multirow[t]{2}{*}{$1 \cdot 9 \cdot, 91$} & 111,1 ro & $1 \wedge 9$ & $\Lambda$ & المتغيرات \\
\hline & & & & التباين \\
\hline قيمة ف & المربعات & درجات الحرية & مجموع مربعات & مصدر الاختلاف \\
\hline \multirow[t]{3}{*}{$\wedge r, q 1$} & $\leqslant 0 \leqslant \vee 0.07$ & 1 & $\leqslant 0 \leqslant \vee 0,0\}$ & بين المجموعات \\
\hline & $0 \leqslant 1, \leqslant 9$ & $1 \varepsilon$ & 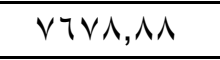 & داخل المجموعات \\
\hline & & 10 & $0 T 10 \leqslant, \leqslant \leqslant$ & الاجمالي \\
\hline
\end{tabular}


جدول(11): اختبار (ت) للفروق بين اراء الاخصائي الاجتماعي والاباء تجاه دور مجالس

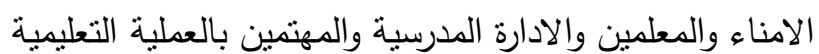

\begin{tabular}{|c|c|c|}
\hline الاباء & الاخصائي & الاستـلال الاحصائي \\
\hline$r q, 1 V$ & 19 & المتوسط \\
\hline$\Gamma 0, r v$ & $v 1, r$ & التباين \\
\hline \multirow[t]{7}{*}{7} & 7 & العبارات أو المشاهدات \\
\hline & Or,YA & Pooled Variance \\
\hline & . & الاختبار للفروض بين متوسطين \\
\hline & 1. & Df \\
\hline & $r, \Sigma)-$ & قيمة ت المحسوبة \\
\hline & $\cdot, \cdot 1 \wedge r$ & أقل فرق معنوي \\
\hline & $1, \wedge 1$ & قيمة ت الجدولية \\
\hline
\end{tabular}

مناقشة نتائج الدراسة:

• تبين مناقثة دور الادارة المدرسية في تقديم العون والمساعدة والخبرة لمجالس الامناء والمعلمين وجود علاقة ذات دلاله احصائية بين دور الادارة المدرسية ومساعدة مجلس لإنس

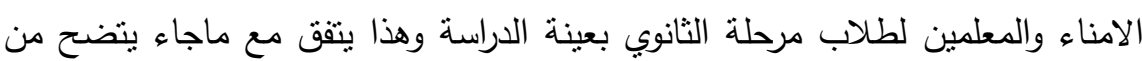

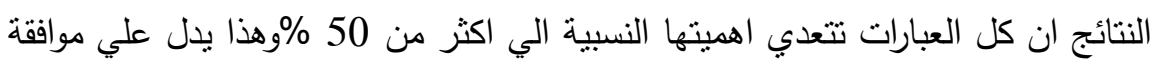

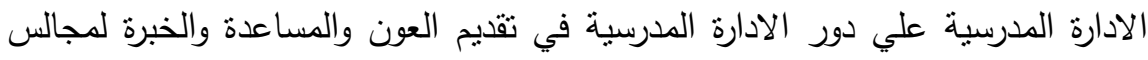

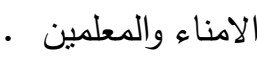
• أما عن أهمية دور الاخصائي الاجتماعي ودور المجلس لطلاب مرحلة الثانوي يتضح من

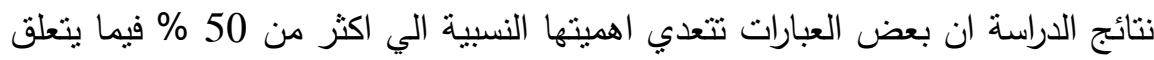
الادوار التي يقوم بها الاخصائي الاجتماعي داخل مجلس الامناء والمعلمين، بينما بعض من لهن

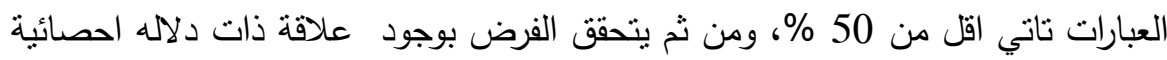
بين دور الاخصائي الاجتماعي ودور المجلس لطلاب مرحلة الثانوي بعينة الدراسة . • كما تبين من نتائج الدراسة وجود علاقة ذات دلاله احصائية بين دور الاخصائي الاجتماعي ودور المجلس في تحقيق قيم المواطنة لطلاب مرحلة الثانوي بعينة الدراسة . 302

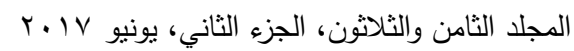


وأخيرا تأكد وجود علاقة ذات دلاله احصائية بين اعضاء المجتمع المدني ودور المجلس لطلاب مرحلة الثانوي بعينة الدراسة . ومن ثم يمكن القول اتفاق الدراسة مع العديد من الدراسات: ومنها دراسة دراسة تامر محمد بـانه

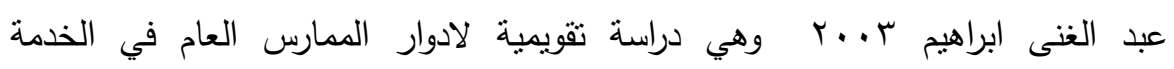
الاجتماعية بمجالس الاباء والمعلمين وواستخدمت منهج المسح الاجتماعي بالحصر درائر

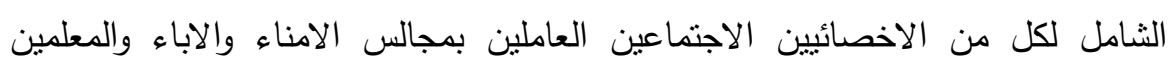
وموجهي التربية الاجتماعية واعضاء مجالس الاباء والمعلمين والمكتب التنفيذي بكل الإهل مدرسة واستخدمت استبيأن لأولياء الامور والمعلمين واعضاء مجاء مالس الاباء والمعلمين بالمدارس الثأنوية العامة هناك فروق في النسب بين استجابات المبحوثين الاخصائيين

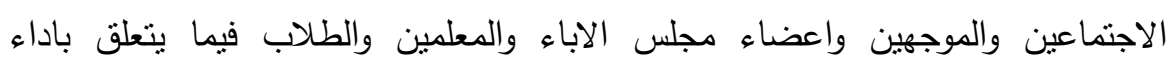

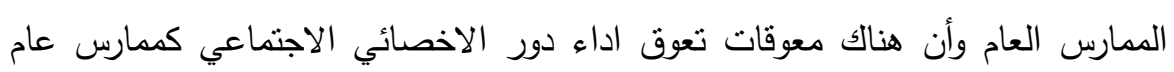
وايضا توجد صعوبات تواجه اعضاء مجالس الاباء والمعلمين والطلاب.

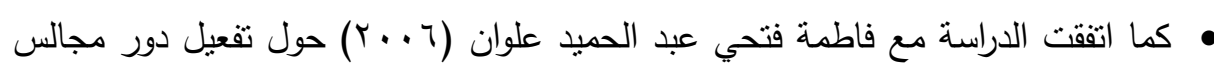
الاباء والمعلمين في ادارة مدارس التعليم العام والخاص مع التطبيق على محافظة الثرقية وأن مجالس الاباء والمعلمين بالمدارس الحكومية لا تهنم بتحقيق التواصل الفعال بين

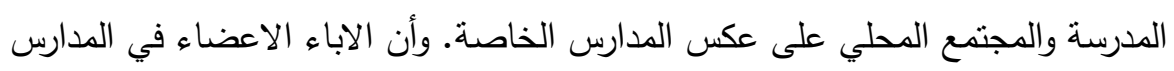
الحكومية لا يشتركون مع ادارة المدرسة في تتظيم العملية التعليمية.



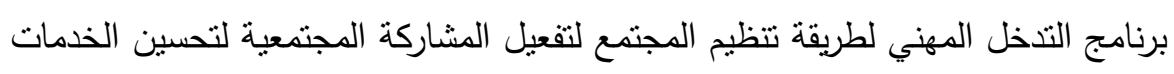
المقدمة لطلاب التعليم الفني، لتفعيل مجالس الاباء والامناء والمعلمين في تحسين لفين الخدمات التعليمية، تحسين الخدمات الاقتصادية، في تحسين الخدمات الصحية.

\section{أهم التوصيات التي نتجت عن الاراسة:}

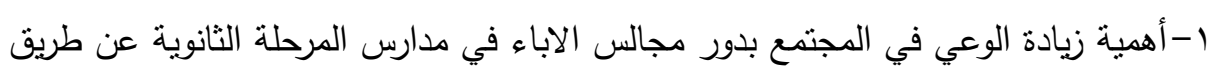

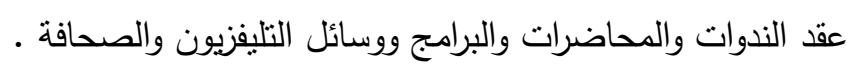

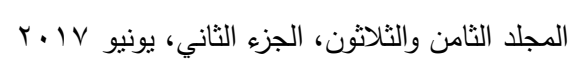


r-العمل علي تحديد مواعيد ملائمة نتتاسب وجميع اولياء الامور وتوجيه الدعوات بوقت كاف والتاكيد عليها لضمان حضور أعضاء المجلس بكاملة من اجل نجاح المجلي في تفعيل واداء دورة

r-وضع نماذج لخطط متكاملة لصلاحيات وفعاليات مجالس الاباء وضرورة متابعتها من قبل

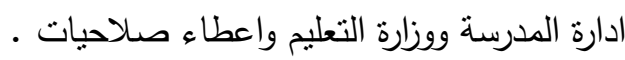

ع-تتكيل واشراك مجالس الامناء من بعض اولياء الامور الذين تتوافر لديهم خبرة وفاعلئ في هذا المجال .

ه-توفير الامكانات المادية والمعنوية الكافية اللازمة لنجاح مجالس الامناء مثل الموازنة

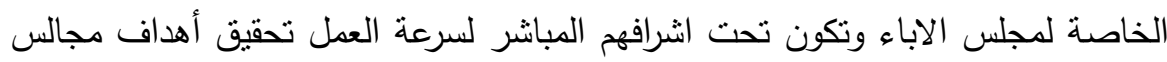
الامناء .

؟-توفير المكان المناسب لعقد الاجتماعات منل توفير قاعة الاجتماعات مخصصة لاجتماعات مجالس الامناء .

V-تكريم الدولة والجهات المختصة لافضل مجالس الاباء وابراز دورهم الفعال وعرض ابرز

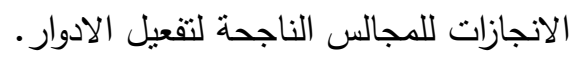
^-ان تسمح ادراة المدرسة من الامناء والمعلمين من اعضاء المجلس بالاطلاع علي الادورلي السجلات المدرسية الخاصة بها حيث انهم يشاركون في العملية التعليمية حتي يكون ارائهم الهن وقراراتهم يخدم العملية التعليمية 9-تفعيل درو مجالس الامناء من خلال تحقيق الاهداف التي تم وضعها فيما يتعلق في تحقيق وترسيخ قيم المواطنة . • 1-تفعيل درو مجالس الامناء من خلال تحقيق الاهداف التي تم وضعها فيما يتعلق في تحقيق وترسيخ قيم المواطنة بين اعضاء المجتمع المدني ( الددرسة الاسرة الجمعيات الخ) 1) ا-حقيق اهداف مجالس الامناء والقضاء علي المظاهر السلبية الني تعترض مجالس الامناء 


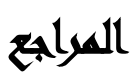

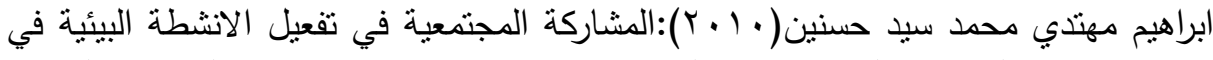

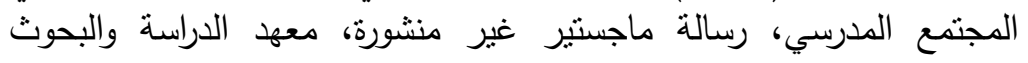
البيئية، جامعة عين شمس.

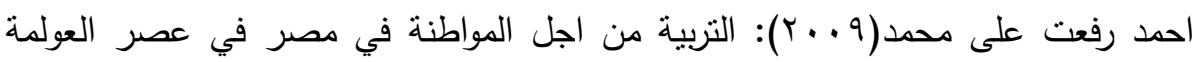


شمس تصنة

امل عادل طه البهائي(1) (ب): دراسة تقويمية لدور مجالس الامناء والاباء والمعلمين

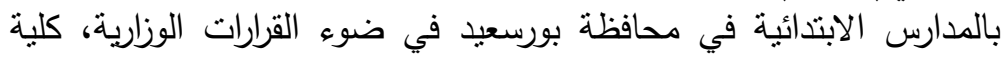
التربية، جامعة بورسعيد الابتية

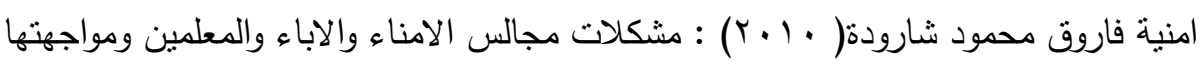

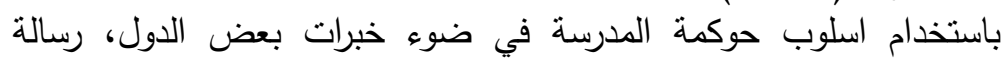

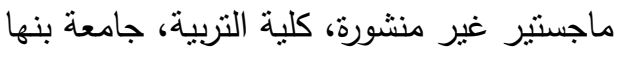

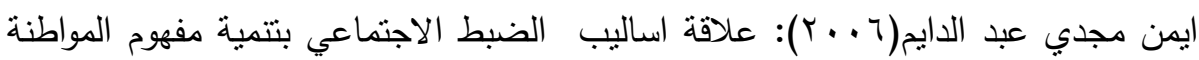

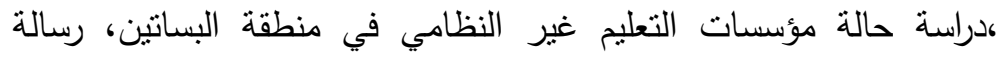
ماجسنير غير منشورة، معهد البحوث والدراسات العربية، جامعة الدول العربية.

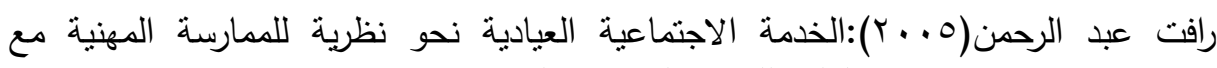
الاقراد؛ دار العلوم للنشر والتوزيع ؛ القاهئة التهرة

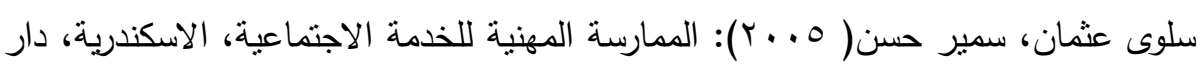

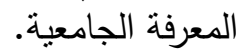



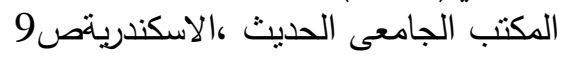

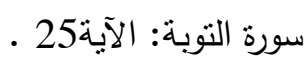

عامر الثماخ : فكرة المواطنة بين النظرية والتطبيق، دار الصحوة، القاهرة ،

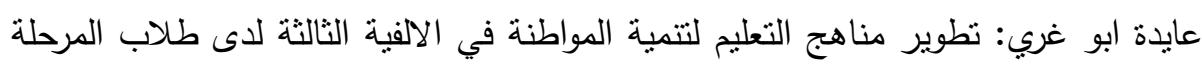

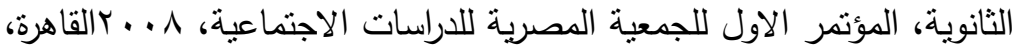

جامعة عين شمس التمس الانس

عبد الباسط عبد المعطي(1919 ()): اتجاهات نظرية في علم الاجتماع ،عالم المعرفة، عدد ؟ ؟

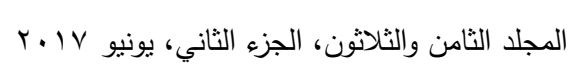




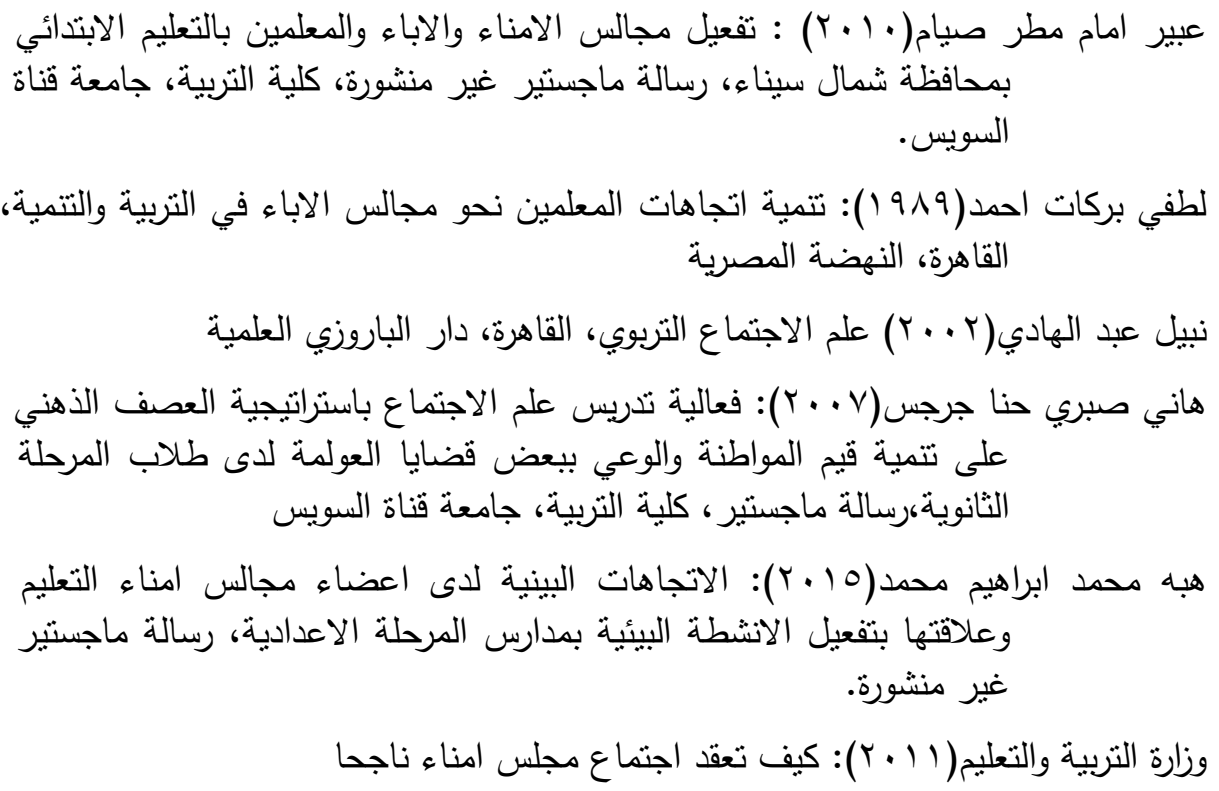

Mo Kyung Hwan : " Citizenship Education for Korean - American Youth " Phd, University of California Berkeley ,2000

Lei Joy Loo: "Claims to belonging and difference : Cultural

Citizenship and Identity Construction in schools " phd, the university of Wisconsin Madison , 2001

. HYPERLINK"http://vb.elmstba.com/t208137.html" 
مصطفى ابراهيم عوض وآخرون

\title{
THE ROLE OF BOARD OF TRUSTEES AND TEACHERS IN ACHIEVING VALUES OF CITIZENSHIP AMONG SECONDARY STAGE STUDENTS
}

Awad, M. I. ${ }^{(1)}$; Mahmoud, A. A. ${ }^{(2)}$ and Mohamed, Rehab, T. F. ${ }^{(3)}$ 1) Institute of Environmental, Ain Shams University. 2) The National Center for Educational Evalution

\begin{abstract}
the role of boards of Trustees and teachers in the development of a culture of citizenship by way of exercising their democratic atmosphere where cares everything happening within the school with the goal of improvement and development, boards of Trustees and teachers can be an effective tool in the care and protection of the culture of citizenship within schools. The study aims to identify the role of boards of Trustees and teachers in achieving citizenship values And areas of participation among educational institutions such as family and school as lowly material/educational institutions in a person's life, the most important values of citizenship which should be nurtured boards of Trustees and teachers used descriptive study using a sample of some secondary schools study society in Giza tutorials, The study used descriptive by using a sample of some secondary schools study society in Giza, educational study tools used are questionnaire for collecting data on the subject of the role of boards of Trustees and teachers in achieving citizenship values, the sample of the study consisted of (210) broken down as follows (40) students (40) tagged (40) specialist (40) parents (50) members of civil society, The study has several results statistically significant relationship exists between the role of school management and assist the Board of Trustees and teachers of secondary level students study sample and there is a statistically significant relationship between the role of the social worker and the role of the Council for

$$
\text { r.lV المجلد الثامن والثلاثثن، الجزء الثاني، يونيو }
$$
\end{abstract}


مجلة العلوم البيئية

معهد الدراسات والبحوث البيئية - جامعة عين شمس

secondary level students study sample, there is a statistically significant relationship between the role of the social worker and the role of the Council in achieving citizenship values for secondary level students study sample. 